\title{
Are We Looking for Loads in All the Right Places? New Research Directions for Studying the Masticatory Apparatus of New World Monkeys
}

\author{
CHRISTOPHER J. VINYARD, ${ }^{1 *}$ ANDREA B. TAYLOR, ${ }^{2,3}$ MARK F. TEAFORD, ${ }^{4}$ \\ KENNETH E. GLANDER, ${ }^{3}$ MATTHEW J. RAVOSA, ${ }^{5,6,7}$ JAMES B. ROSSIE, ${ }^{8}$ \\ TIMOTHY M. RYAN, ${ }^{9}$ AND SUSAN H. WILLIAMS ${ }^{10}$ \\ ${ }^{1}$ Department of Anatomy and Neurobiology, Northeast Ohio Medical University, \\ Rootstown, Ohio \\ ${ }^{2}$ Department of Community and Family Medicine, Duke University School of Medicine, \\ Durham, North Carolina \\ ${ }^{3}$ Department of Evolutionary Anthropology, Duke University, Durham, North Carolina \\ ${ }^{4}$ Department of Physical Therapy, School of Health Sciences, High Point University, \\ High Point, NC \\ ${ }^{5}$ Department of Biological Sciences, University of Notre Dame, Notre Dame, Indiana \\ ${ }^{6}$ Department of Aerospace and Mechanical Engineering, University of Notre Dame, \\ Notre Dame, Indiana \\ ${ }^{7}$ Department of Anthropology, University of Notre Dame, Notre Dame, Indiana \\ ${ }^{8}$ Department of Anthropology, Stony Brook University, Stony Brook, New York \\ ${ }^{9}$ Department of Anthropology and Center for Quantitative Imaging, EMS Energy \\ Institute, Pennsylvania State University, University Park, Pennsylvania \\ ${ }^{10}$ Department of Biomedical Sciences, Ohio University Heritage College of Osteopathic \\ Medicine, Athens, Ohio
}

\begin{abstract}
New World monkeys display a wide range of masticatory apparatus morphologies related to their diverse diets and feeding strategies. While primatologists have completed many studies of the platyrrhine masticatory apparatus, particularly morphometric analyses, we collectively acknowledge key shortcomings in our understanding of the function and evolution of the platyrrhine feeding apparatus. Our goal in this contribution is to review several recent, and in most cases ongoing, efforts to address some of the deficits in our knowledge of how the platyrrhine skull is loaded during feeding. We specifically consider three broad research areas: (1) in vivo physiological studies documenting mandibular bone strains during feeding, (2) metric analyses assessing musculoskeletal functional morphology and performance, as well as (3) the initiation of a physiological ecology of feeding that measures in vivo masticatory mechanics in a natural environment. We draw several conclusions from these brief reviews. First, we need better documentation of in vivo strain patterns in the platyrrhine skull during feeding given their empirical role in developing adaptive hypotheses explaining masticatory apparatus form. Second, the greater accuracy of new technologies, such as CT scanning, will allow us to better describe the functional consequences of jaw
\end{abstract}

Grant sponsor: NSF; Grant numbers: BCS-094666, BCS0412153, BCS-9908847, BCS-0100825, BCS-0959438, BCS/IOS0924592, BCS-0720028/0720025, BCS-0552285, BCS-0507074, BCS 0452160; Grant sponsor: NIH; Grant number: R24 HD050837.

*Correspondence to: Christopher J. Vinyard, Department of Anatomy and Neurobiology, Northeast Ohio Medical University,
4209 State Route 44, P.O. Box 95, Rootstown, OH 44272.

E-mail: cvinyard@neomed.edu

Received 15 September 2011; Accepted 16 September 2011

DOI 10.1002/ar.21512

Published online 1 November 2011 in Wiley Online Library (wileyonlinelibrary.com). 
form. Third, performance studies are generally lacking for platyrrhine jaws, muscles, and teeth and offer exciting avenues for linking form to feeding behavior and diet. Finally, attempts to bridge distinct research agendas, such as collecting in vivo physiological data during feeding in natural environments, present some of the greatest opportunities for novel insights into platyrrhine feeding biology. Anat Rec, 294:2140-2157, 2011. (C) 2011 Wiley Periodicals, Inc.

\section{Key words: platyrrhines; masticatory apparatus; feeding}

Diet and feeding behaviors are widely recognized as key components of primate natural history and evolution (e.g., Richard, 1985; Conroy, 1990; Martin, 1990; Fleagle, 1998; Campbell et al., 2007). Not surprisingly then, primatologists have put forth significant effort in trying to understand how the morphology and function of the primate feeding apparatus relate to diet and feeding behaviors. We have learned a great deal about masticatory functional morphology in primates from research on the physiology of feeding, comparative morphometrics of skulls, jaw muscles, and teeth as well as studies of feeding ecology. As often occurs in research, some clades come to be better studied because early work sets the stage for future advancement-a form of "research inertia." Among primates, the in vivo data describing the mechanics of mastication in Old World monkeys have made this group the model for studying the functional morphology of the masticatory apparatus. Moreover, the phylogenetic proximity of Old World monkeys to humans and the benefits this relationship confers for studying fossil hominins (e.g., Hylander, 1988; Daegling and Grine, 1991) likely adds to the differential focus on this group. By comparison, we know less about the functional morphology of the platyrrhine masticatory apparatus, although recent efforts point to a renewed interest in this group. Our goal in this contribution is to consider several of our recent and ongoing efforts in physiological, morphometric, and ecological research of New World monkeys that may help to better understand how loads are generated and dissipated in the platyrrhine skull during feeding. We hope that some of these ideas will initiate further advances in the understanding of the platyrrhine masticatory apparatus.

\section{IN VIVO RESEARCH ON PLATYRRHINE FEEDING MECHANICS}

The majority of in vivo data describing how the primate skull is loaded during feeding is based on research involving Old World monkeys (e.g., Hylander, 1979a,b,c, 1984, 1985; Hylander et al., 1987, 1991; Hylander and Johnson, 1992). These studies of catarrhine monkeys provide most of the empirical basis for identifying which parts of the skull we think experience significant loads during feeding and what types of loads occur in these regions. We routinely translate these in vivo data into morphological predictions as a physiological criterion for interpreting variation in skull form across anthropoids (e.g., Hylander 1979b, 1985, 1988; Bouvier, 1986a; Ravosa, 1991a; Daegling, 1992; Anapol and Lee, 1994; Ravosa et al., 2000a; Taylor, 2002; Vinyard et al., 2003). This extrapolation is essential given the impossibility of collecting in vivo data for every primate species. We know, however, that our functional interpretations based on these predictions can be flawed as new in vivo data can reveal novel loading regimes or muscle activity patterns invalidating previous extrapolations (e.g., Hylander and Bays, 1979; Hylander and Johnson, 1997; Larson and Stern, 2007; Williams et al., 2009).

Compared to Old World monkeys, we know much less about how the skull is loaded during feeding in platyrrhines. Most of the platyrrhine in vivo strain data are from the circumorbital region of owl monkeys (Aotus sp.) and address functional questions related to the evolution of the anthropoid postorbital septum (Ross and Hylander, 1996; Ross, 2001). These data suggest a complicated loading pattern including bending and twisting regimes, relatively low magnitude strains compared to the mandible and a general similarity to loading patterns in Old World monkeys and strepsirrhines (Ross and Hylander, 1996; Ravosa et al., 2000b; Ross, 2001, 2008). Published data on mandibular corpus strains indicate that owl monkeys are more similar to macaques in their working- to balancingside strain ratios during mastication than either is to galagos suggesting that symphyseal fusion in anthropoids facilitates increased balancing-side muscle force recruitment (Hylander et al., 1998). Additionally, owl monkeys conform to a primate-wide, and potentially tetrapod-wide, pattern where strain magnitudes across cranial bones decrease in relation to their distance from the masticatory apparatus (Ross and Metzger, 2004).

While these data suggest some basic similarities in craniofacial loading between New and Old World monkeys, we simply do not know very much about the specific loads that platyrrhine jaws experience during feeding. For example, Ross et al. (2010) provide the only data describing loading regimes in the mandibular corpus. Their results indicate that the capuchin corpus is bent, twisted, and sheared during premolar biting of hard objects. Beyond this initial report, we lack detailed data on loading of the platyrrhine mandibular symphysis or other regions of the face.

If New World monkeys load their jaws similarly to their Old World counterparts, then the lack of in vivo data for platyrrhines may have limited consequence as we can reasonably assume correspondence between the anthropoid infraorders. Strain patterns, however, are at least partly influenced by jaw geometry. Unfortunately, sufficient differences exist in the details of skull morphology and jaw-muscle activity patterns between the infraorders to suggest a potential divergence in feeding mechanics. These differences may challenge using macaques as an in vivo model for understanding the functional significance of platyrrhine jaw form. 
Bouvier (1986b) demonstrated that New World monkeys possess relatively long mandibles, with deep and mediolaterally thin corpora, and relatively narrow condyles compared to Old World monkeys. Bouvier interpreted these differences to indicate reduced corporal twisting and reduced condylar loading. More reasonably, these differences only point to a reduced ability to resist these potential loads as assessment of jaw morphology cannot demonstrate loading regimes. Eaglen (1984) found that platyrrhines possess relatively smaller incisors than catarrhines and attributed some of these differences to size-related variation in diet. Comparisons of jaw-muscle recruitment patterns during chewing indicate that New World monkeys differ from other primates in the timing of masseter recruitment during the power stroke (Hylander et al., 2000; Vinyard et al., 2007). The divergent recruitment pattern may correlate with both the previously described morphological variation and suggests possible differences in jaw loading regimes. Similarly, Vinyard and Taylor (2010) compared electromyography (EMG) activity levels to jaw-muscle architecture and singled out platyrrhines as potentially different from other primates in their relationship between architecture and muscle activation. Outside of the masticatory apparatus, comparative studies have identified differences in platyrrhine and catarrhine skulls suggesting the possibility of distinct evolutionary pressures in these clades since their split from a common ancestor (Delson and Rosenberger, 1984; Rosenberger, 1986; Ravosa 1991b; Ross and Ravosa, 1993; Armfield and Vinyard, 2010). Collectively, these comparative data suggest that further investigation of in vivo strain patterns in platyrrhines would be useful for understanding the functional morphology of their masticatory apparatus.

We present a preliminary look at strain patterns in the mandibular corpus and symphysis of a tufted capuchin (C. apella) to stimulate discussions of in vivo loading patterns between the anthropoid infraorders during mastication. Rosette strain gages were bonded to the inferior border of the right mandibular corpus below the $\mathrm{P}_{4}$ and the infero-labial aspect of the symphysis at the midline in an adult female (Fig. 1). Strain patterns in the mandibular corpus during almond chewing differ between working and balancing sides (Fig. 2). On the working (i.e., right) side, shear strains are fairly low $(\bar{x}=230 \mu \varepsilon, \mathrm{SD}= \pm 89 \mu \varepsilon)$, which is not surprising given the lack of significant mechanical challenges posed by almonds (Williams et al., 2005). The orientation of principal tensile strain $\left(\varepsilon_{1}\right)$ on the working-side corpus (Fig. 1) along with a ratio of $\varepsilon_{1}$ to principal compressive $\left(\varepsilon_{2}\right)$ strains near $1.0(\bar{x}=0.9)$ suggests a predominance of corporal twisting with one or more additional loading regimes superposed on it. Balancing-side shear strains $(\bar{x}=241 \mu \varepsilon, \pm 89 \mu \varepsilon)$ are similar to working-side levels suggesting that capuchins follow the anthropoid pattern of maintaining relatively low ratios of working- to balancing-side shear strains in their mandibular corpora (Hylander, 1979a; Hylander et al., 1998). The orientation of principal tensile strain on the balancing-side corpus is more readily interpreted as a combination of parasagittal bending and twisting during the power stroke of mastication (Fig. 1). Although twisting may be more significant in the capuchin corpus, these preliminary data suggest a general similarity with loading regimes in the macaque mandibular corpus (Hylander, 1979a).
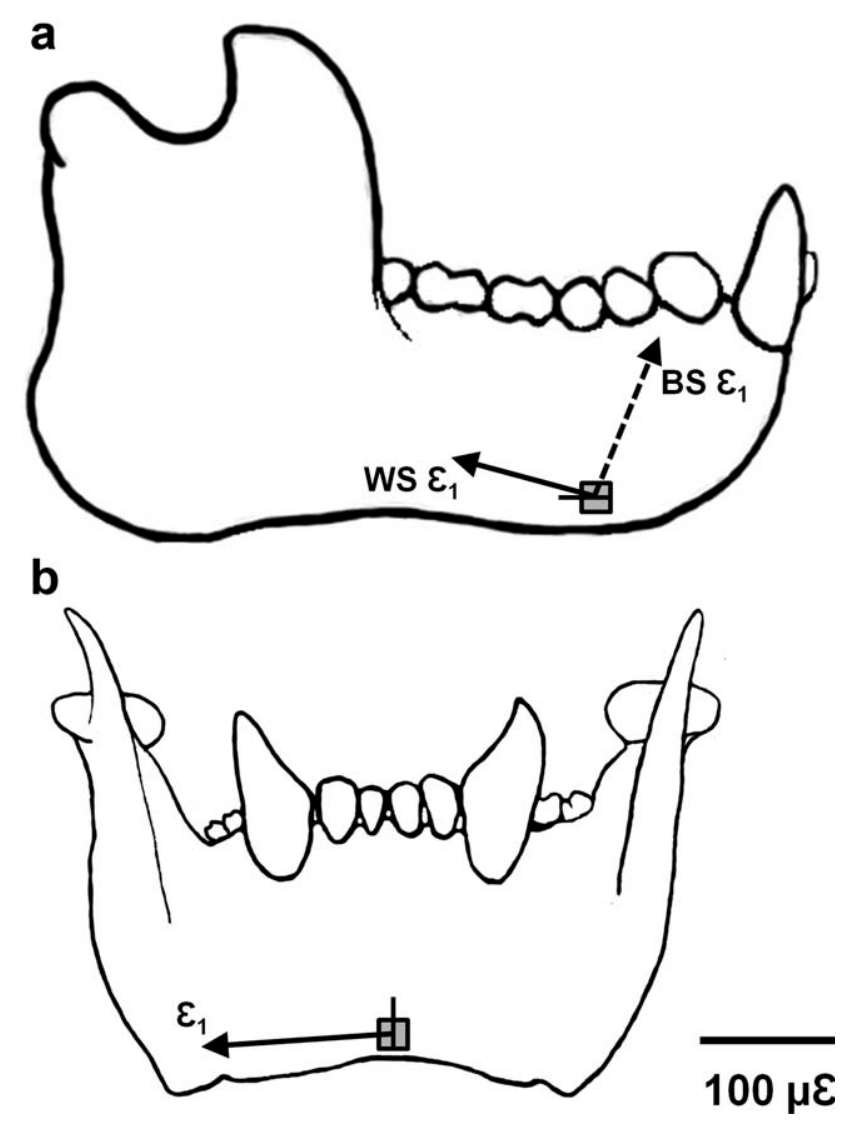

Fig. 1. Drawings of a Cebus apella mandible in (a) lateral and (b) frontal views demonstrating rosette strain gage locations on the corpus and symphysis, respectively. For the corpus gage, the solid arrow demonstrates the average orientation of principal tensile strain $\left(\varepsilon_{1}\right)$ during chewing almonds on the working-side (WS), while the dashed arrow indicates the average orientation of principle tension when the corpus is acting as the balancing side (BS) ( $N=23$ cycles). For the midline symphysis gage, the orientation of principle tension is relatively similar during left- and right-sided chews and is averaged. Principle compressive strains $\left(\varepsilon_{2}\right)$ are oriented at 90 degree to principle tensile strains (not shown). For both gages, the black line demonstrates the axis for determining the angle of principle strain directions. Strain gage implantation, recording, and analysis were completed following previously described protocols (e.g., Hylander, 1979a, 1984).

Symphyseal shear strains along the infero-labial aspect of the symphysis averaged $300 \mu \varepsilon( \pm 112 \mu \varepsilon)$ during almond chewing (Fig. 2). The orientation of principle tensile strains varied slightly between left- (88 degree \pm 3 degree) and right-sided (102 degree \pm 16 degree) chews $(\mathrm{N}=23)$. The average of 94 degree $( \pm 13$ degree $)$ is directed nearly perpendicular to the symphyseal midline (Fig. 1). This orientation of $\varepsilon_{1}$ suggests either frontal bending of the symphysis associated with twisting of the mandibular corpora about their long axes or medial transverse bending of the symphysis. While a hypothesis of frontal bending (where the inferior symphysis is tensed and the alveolar border compressed) fits better with the observed strains from the corpus gage, the ratio of $\varepsilon_{1} / \varepsilon_{2}$ is not consistently above 1.0 as predicted for this loading regime $\left(\varepsilon_{1} / \varepsilon_{2}\right.$ range, $\left.=0.51-1.6 ; \bar{x}=0.95\right)$, suggesting the potential for additional superposed loading 


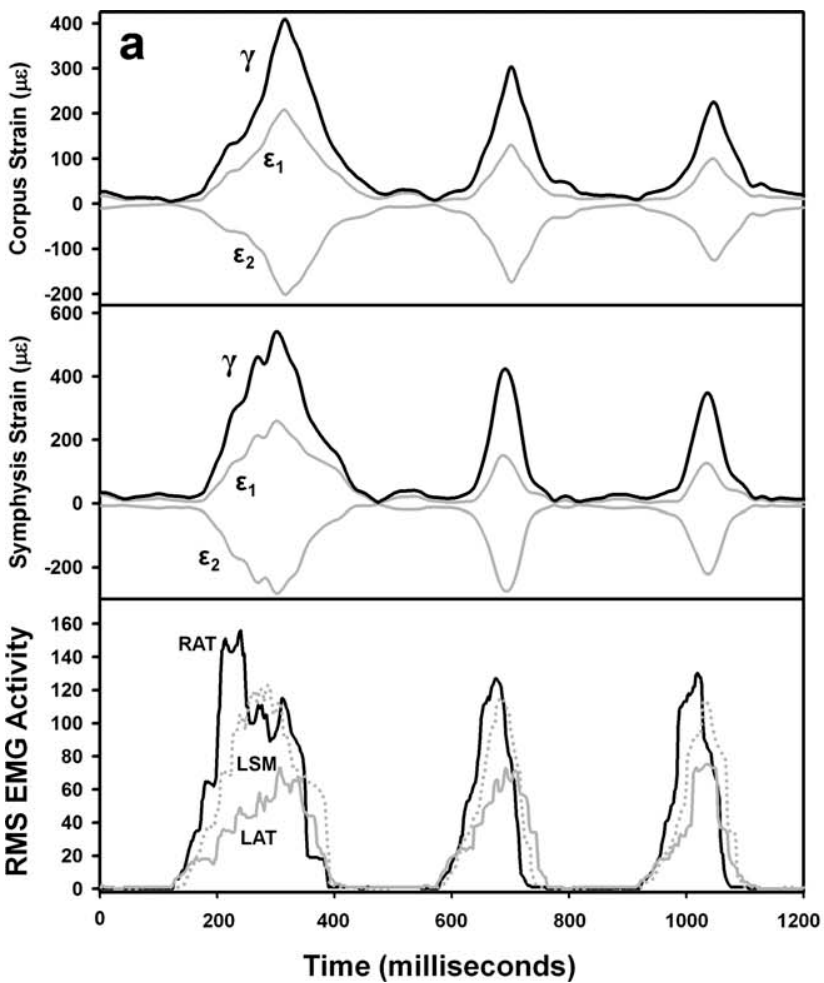

Fig. 2. Plots of corpus and symphysis strains in a C. apella female chewing almonds during a sequence of (a) three right-sided and (b) three left-sided cycles. For both gages, shear $(\gamma)$ strains are depicted as black lines, while tensile $\left(\varepsilon_{1}\right)$ (positive) and compressive $\left(\varepsilon_{2}\right)$ (negative) strains are shown in gray. The lower panel illustrates root mean

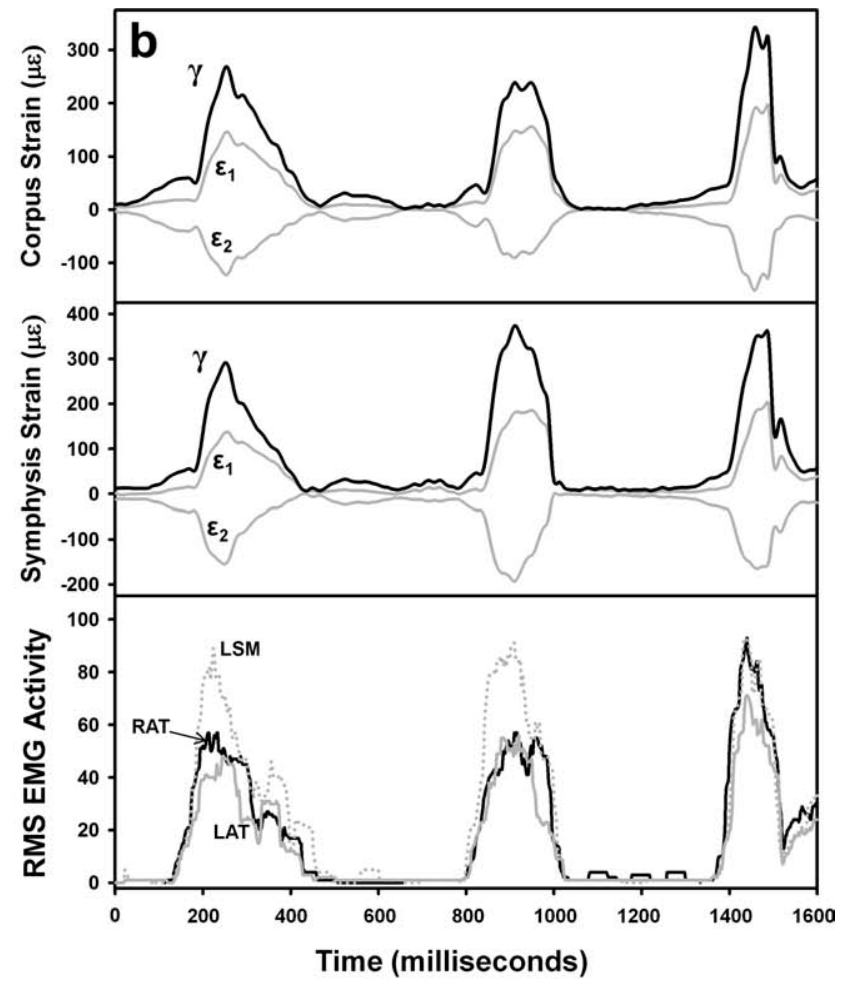

square (RMS) jaw-muscle electromyography recordings for the right anterior temporalis (RAT) (solid black), left anterior temporalis (LAT) (solid gray), and left superficial masseter (LSM) (dotted gray). (The right superficial masseter electrode failed in the experiment).

hypothesize that this shift in jaw-muscle recruitment pattern during mastication may explain the potential difference in symphyseal loading between New and Old world monkeys.

\section{MORPHOMETRICS OF PLATYRRHINE SKULLS, TEETH, AND JAW MUSCLES}

with frontal bending due to twisting of the mandibular corpora. While still very preliminary, the symphyseal loading regimes hypothesized here are sufficiently different from those observed in the macaque symphysis (Hylander, 1984) to justify additional in vivo research into platyrrhine symphyseal loading patterns during mastication. Moreover, Hylander (1984) points out that an inferior transverse torus (i.e., simian shelf) is an effective morphology for resisting frontal bending. Tufted capuchin symphyses possess an obvious simian shelf (Hershkovitz, 1977).

Jaw-muscle electromyography from platyrrhines, including capuchins, suggests a tendency for New World monkeys to contract their working- and balancing-side superficial masseters near simultaneously during the chewing cycle. This recruitment pattern differs from Old World monkeys (Hylander et al., 2000; Vinyard et al., 2007). In conjunction with temporalis activity, this derived recruitment pattern could contribute to both the twisting of the mandibular corpora as well as the frontal bending of their mandibular symphyses as the difference between peak corporal and symphyseal shear strains average $12 \mathrm{msec}$ in this preliminary sample (Fig. 2). We

\section{Mandibular Morphometrics}

Metric comparisons of platyrrhine skulls and teeth have drastically outpaced in vivo studies of chewing mechanics. The majority of morphometric comparisons focus on interpreting the functional consequences of jaw form relative to load resistance and bite force production (Bouvier, 1986b; Cole, 1992; Daegling, 1992; Kinzey, 1992; Anapol and Lee, 1994; Wright 2005; Norconk et al., 2009). Norconk et al. (2009) provide the most recent review of platyrrhine jaw metrics finding that hard-object feeding taxa such as capuchins (Cebus) and pitheciines (Cacajao, Chiropotes, and Pithecia) possess the most robust jaws and relatively improved biting leverage. Alternatively, more folivorous taxa such as howlers (Alouatta) and woolly spider monkeys (Brachyteles) exhibit jaws that are intermediate in robustness and lack mechanical advantage for biting at $\mathrm{M}_{1}$ compared to other platyrrhines. The remaining primarily frugivorous, insectivorous, and gummivorous platyrrhines tend to possess less robust jaws compared to 
these other platyrrhines (Anapol and Lee, 1994; Vinyard et al., 2003; Norconk et al., 2009).

A long-standing prediction in functional studies of jaw shapes contends that species with relatively hard and/or tough diets should have relatively robust jaws due to the magnitude and/or number of repetitive loads experienced during feeding (e.g., Hylander 1979c; Bouvier, 1986b; Ravosa, 1991a, 1996; Daegling 1992; Taylor, 2002; Vinyard et al., 2003). Following on the comparisons in Norconk et al. (2009), more folivorous platyrrhines, such as howlers, do not follow this prediction as they possess jaw shapes that would provide intermediate load resistance despite their relatively high degrees of folivory. Similar questions have been raised about the specific relationships between diet and jaw morphology in Old World monkey clades (Daegling and McGraw, 2001, 2007). While experimental manipulation of diet clearly affects both jaw mechanics (Ahlgren, 1966; Møller, 1966; Hiiemae and Kay, 1973; Hylander et al., 1987, 2000; Hylander and Johnson, 1994; Ottenhoff et al., 1996; Agrawal et al., 1998, 2000; Foster et al., 2006; Woda et al., 2006) and jaw robustness throughout the lifetime (Bouvier and Hylander, 1982; Corruccini and Beecher, 1982, 1984; Ravosa et al., 2007; Menegaz et al., 2009), we have to admit the difficulties in teasing apart the multiple competing influences that impact jaw morphology on the time scale involved in comparisons among primate species (Daegling and McGraw, 2001, 2007; Daegling, 2002; Vinyard and Ryan, 2006; Vinyard, 2008). Some of the biggest challenges we face are determining in vivo loading regimes and linking these loads to mechanical aspects of species diets to make more informed species-level interpretations of primate jaw morphology. For example, howlers choose less tough leaf material during feeding compared to what is available in their habitat (Teaford et al., 2006). This behavioral choice may effectively reduce mechanical loads during chewing and help account for their relatively reduced jaw robusticity compared to hard-object feeding platyrrhines.

Caliper-based measurements provide the foundation of our understanding of primate jaw shapes; however, researchers have begun using several newer technologies to expand on these traditional assessments of jaw shape. For the most part, though, these techniques have not been applied broadly to platyrrhines, leaving many available research opportunities. Significant progress has been made studying mandibular cross-sectional geometry in catarrhines (Daegling, 1989, 1993, 2001, 2002, 2007; Daegling and Grine, 1991). These analyses are important because they more accurately describe the load resisting abilities of the jaw based on the amount and distribution of bone. Still, only two cross-sectional studies of platyrrhine jaws have been conducted and both focus on specific groups of platyrrhines. Daegling (1992) demonstrated increased jaw robusticity in Cebus apella compared to the non-tufted $C$. capucinus, while the second study identified a lack of jaw robusticity in treegouging marmosets compared to non-gouging tamarins and squirrel monkeys (Vinyard and Ryan, 2006; Ryan et al., 2010).

We combine CT scans from Rossie (2006) and Vinyard and Ryan (2006) to provide a first look at variation in cortical area of the mandibular corpus across platyrrhines (Fig. 3). Ln cortical area (CA) at $\mathrm{P}_{4}$ (least-squares
[LS] regression slope $=2.53 ; 95 \% \mathrm{CI}= \pm 0.47)$ scales with strong positive allometry relative to ln jaw length (Fig. 4a). Cortical area at $\mathrm{M}_{2}$ exhibits a similar scaling pattern $(\mathrm{LS}$ slope $=2.60 \pm 0.41$ ) (data not shown). The scaling of these cross-sectional estimates suggest stronger positive allometry of CA compared to a caliper-based estimate of cortical area (i.e., as an ellipse using external corpus depth and width) (LS slope $=2.29 \pm 0.25, \mathrm{~N}=$ 18). The cross-sectional estimate suggests that cortical areas may be increasing more rapidly with size across New World monkeys than might be expected based on external appearance. Examination of cortical area shape $\left(\mathrm{CA}^{0.5} /\right.$ jaw length) supports previous arguments based on external measurements that hard-object feeding capuchins and pitheciines tend to have relatively robust jaws (Fig. 4b; see also Fig. 3). Despite their larger size, the more folivorous Alouatta is intermediate in CA, while several smaller frugivorous, insectivorous, and gummivorous species maintain relatively reduced cortical areas (Fig. 4b). Interestingly, Callicebus exhibits a relatively large cortical area at $\mathrm{P}_{4}$ (and $\mathrm{M}_{2}$; data not shown) (Fig. 4b). This result is consistent with previous observations of relatively large molars in Callicebus (Pirie, 1978) as well as their consumption of a large percentage of leaves and seeds, with seeds being important during the cooler, lean season (Kinzey, 1974; Heiduck, 1997). Future research exploring the cross-sectional morphology of platyrrhine jaws will be important in demonstrating the functional consequences of variation in internal jaw form throughout the clade.

In addition to cross-sectional analyses, assessment of bone material properties in the jaws of catarrhines has been important in describing how bone microstructural variation impacts load resistance abilities in the mandible during feeding. Microstructural analyses of catarrhines have focused on (1) documenting variation in material properties throughout the skull during ontogeny and between species (Dechow et al., 1993, 2010; Peterson and Dechow, 2003; Rapoff et al., 2008; Wang et al., 2010), (2) describing how variation in stiffness and directionality of elastic properties relate to differences in load resistance abilities (Dechow et al., 1993, 2010; Daegling et al., 2008, 2009, 2011a,b; Daegling and McGraw, 2009; Wang et al., 2010), (3) interpreting in vivo strains as patterns of bone stress during mastication (Dechow and Hylander, 2000), and (4) improving finite-element modeling of jaw biomechanics (Wang and Dechow, 2006). As pointed out in several of these studies, an improved comparative dataset is needed to fully explore the functional consequences of microstructural variation in bone properties. This point is particularly relevant to platyrrhines where this level of variation in bone properties remains essentially untouched in studies of craniofacial functional morphology.

Examining how the symphysis performs in resisting in vitro loads represents another area of research that will improve our understanding of platyrrhine jaw functional morphology. Recently, Hogg et al. (2011) loaded platyrrhine symphyses to failure in simulated lateral transverse bending (i.e., wishboning) and dorso-ventral shear to compare symphyseal strength in tree-gouging marmosets to other non-gouging platyrrhines. They found that marmosets exhibit a relatively reduced ability to withstand external forces in their symphyses (Hogg et al., 2011). This result links symphyseal performance 


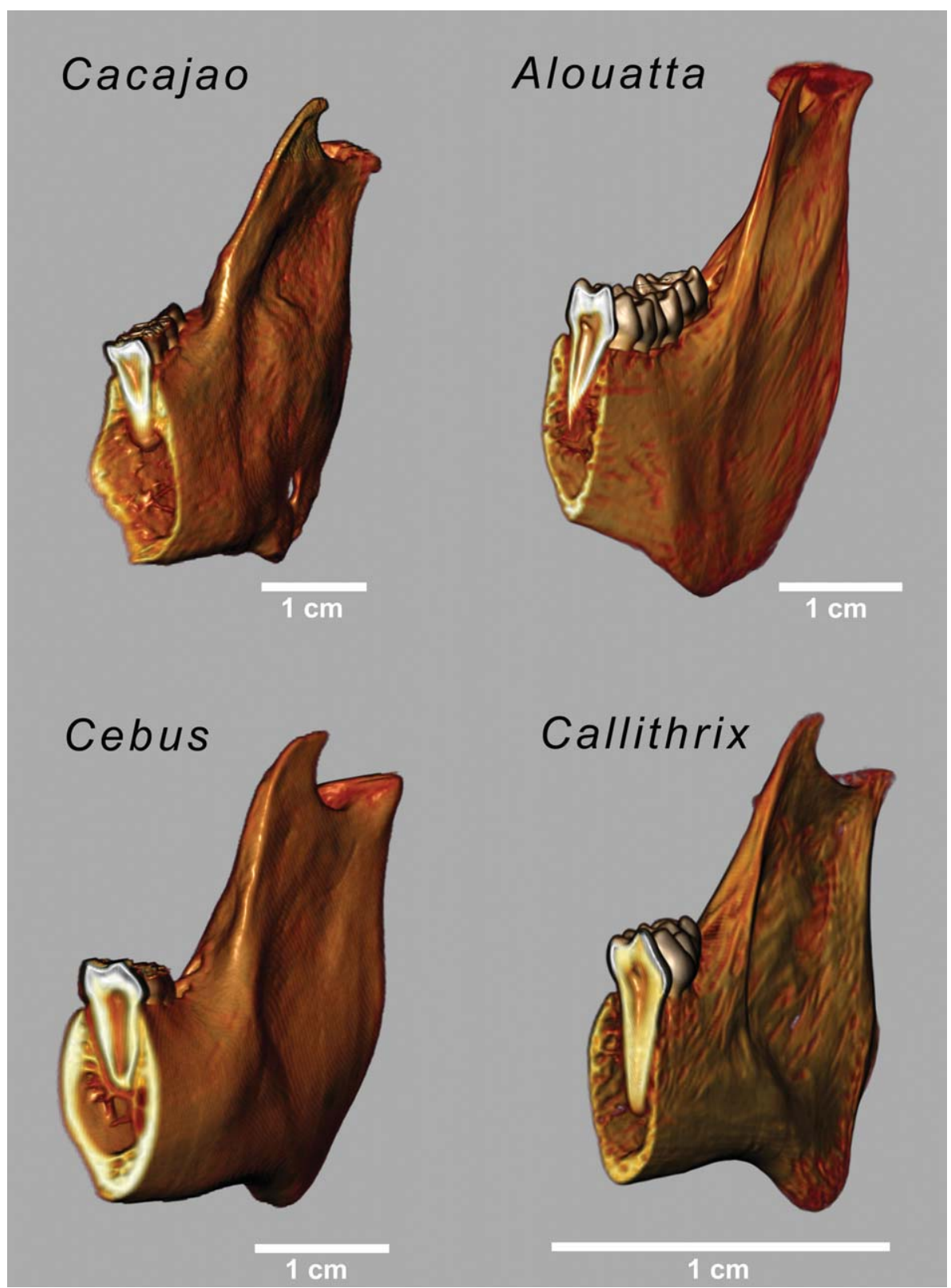

Fig. 3. $\mu \mathrm{CT}$ reconstructions of platyrrhine jaws demonstrating variation in cortical morphology of the mandibular corpus at $\mathrm{P}_{4}$ for two hard-object feeders (Cacajo and Cebus), a folivore (Alouatta) and tree- gouger (Callithrix). All specimens are scaled to approximately similar corporal heights. The white scale bar below each jaw indicates $1.0 \mathrm{~cm}$. Reconstructions generated in Avizo 3D visualization software (6.2; VSG). to morphological comparisons between these groups (Vinyard et al., 2003; Vinyard and Ryan, 2006), suggesting that marmoset jaws do not offer improved load resistance abilities against habitual loads generated during mastication.

To further consider the potential of in vitro performance studies for evaluating the functional consequences of symphyseal form in platyrrhines, we assessed whether symphyseal shape helps dictate the location of failure during simulated lateral transverse bending (Fig. 5). These preliminary data suggest that more "v-shaped" symphyses (i.e., long and narrow) are more likely to fail at the midline during lateral transverse bending com- pared to "u-shaped" morphologies (Fig. 6). Based on this result, we hypothesize that symphyseal shape will affect where failure occurs during loading. This hypothesis builds on the argument that long and narrow jaws concentrate symphyseal stresses in lateral transverse bending (Hylander, 1984, 1985; Hylander and Johnson, 1994; Vinyard and Ravosa, 1998; Daegling, 2001). Moreover, the significant percentage of platyrrhine symphyses that failed off-midline suggest that fusion of the symphysis provides sufficient midline robusticity that other areas of the symphyses, such as segments associated with the large canines, become relatively weak (see Williams et al., 2008a). 


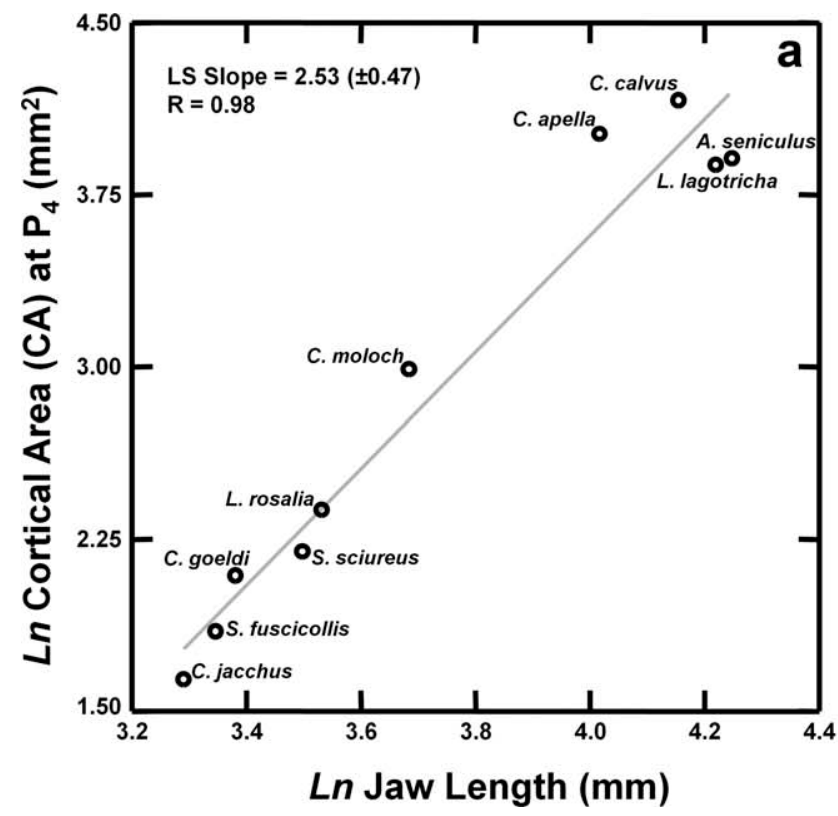

Fig. 4. Plots of (a) cortical area (CA) and (b) cortical area shape (CA $\mathrm{C}^{0.5}$ /jaw length) at $\mathrm{P}_{4}$ versus jaw length across 10 platyrrhine species. The regression slope estimate of $2.53( \pm 0.47)$ suggests that In cortical area scales with positive allometry (where isometry $=2.0$ ) relative to In jaw length. Similarly, the trend for cortical area shape to increase with jaw length $(r=0.59, P=0.07)(b)$ tracks this size-correlated change in shape. Data for $C$. jacchus, $S$. fuscicollis and $S$. sciureus are taken from Vinyard and Ryan (2006), while data for all remaining species are taken from scans described by Rossie (2006).

\section{Dental Metrics}

Similar to the bones of the masticatory apparatus, there have been numerous metric analyses of platyrrhine teeth. Much of this work has addressed how tooth size and shape (Zingeser, 1973; Kinzey, 1974, 1992; Kay, 1975; Rosenberger and Kinzey, 1976; Hershkovitz, 1977; Rosenberger, 1978, 1992; Eaglen, 1984; Teaford, 1985; Greenfield, 1992; Spencer, 2003; Wright, 2005; Norconk et al., 2009) as well as dental microstructure (Gantt, 1980; Nogami and Yoneda, 1983; Nogami and Natori, 1986; Maas and Dumont, 1999; Martin et al. 2003; Hogg, 2010; Ravosa et al., 2010; Hogg et al., 2011) relate to resisting loads during feeding on different diets. Because tooth wear and breakage can significantly affect food intake, exploring the relationships between dental form and function provides important insights into platyrrhine feeding biology. Very broadly speaking, these studies show that platyrrhines subscribe to trends identified throughout primates where occlusal relief is linked to folivory and insectivory while dental robusticity is related to hard-object feeding.

Lucas et al. have recently applied engineering theory involving fracture mechanics to generate several predictions relating enamel structure to mammalian diets (Lucas et al., 2008a,b; Chai et al., 2009; Lawn et al., 2009). These efforts follow previous work exploring how dietary material properties relate to occlusal shape in the primate dentition (Lucas, 2004). This primarily theoretical work is significant because it marries enamel morphology throughout the tooth to fracture mechanics,

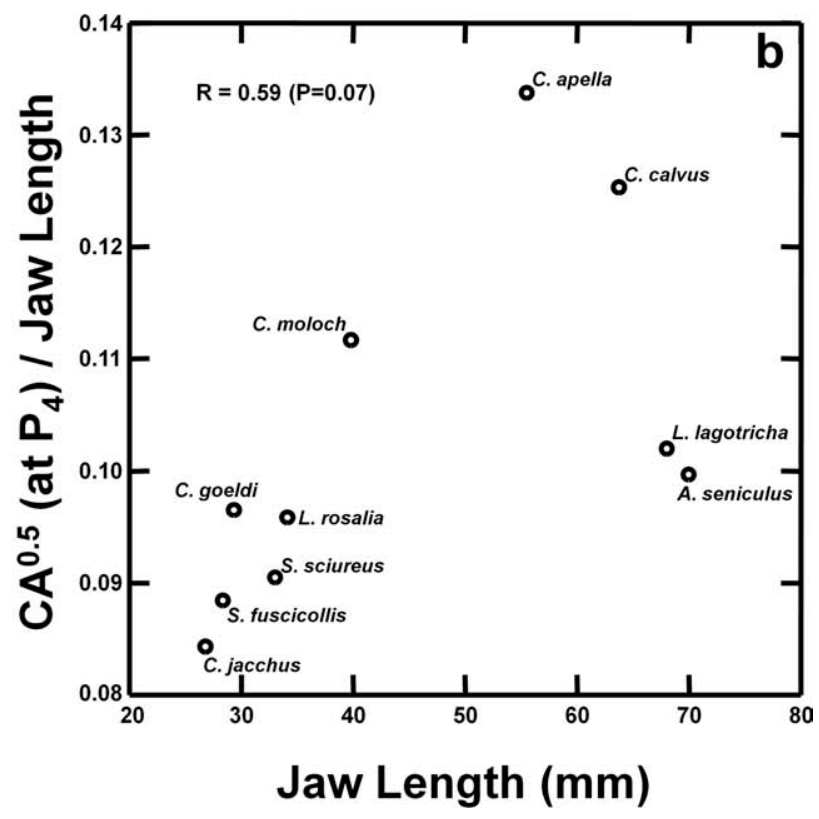

These cortical areas were estimated using MacroMomentJ v1.3 (Warfel, 1997) in ImageJ. (Abbreviations: LS Slope = Least-squares regression slope; $\mathrm{R}=$ Product-moment correlation coefficient; $C$. calvus = Cacajao calvus; C. apella = Cebus apella; A. seniculus = Alouatta seniculus; L. lagotricha $=$ Lagothrix lagotricha; C. moloch $=$ Callicebus moloch; L. rosalia $=$ Leontopithecus rosalia; C. goeldii $=$ Callimico goeldii; S. fuscicollis = Saguinus fuscicollis; S. sciureus = Saimiri sciureus; C. jacchus $=$ Callithrix jacchus).

providing explicit predictions linking regional enamel form to dietary processing via tissue engineering principles. Fortunately, some of the basic morphological data on enamel morphology are available to test these predictions in platyrrhines (Nogami and Yoneda, 1983; Nogami and Natori, 1986; Hogg, 2010; Hogg et al., 2011). Moreover, the dietary diversity across platyrrhines makes them a compelling group for assessing whether enamel structure follows predicted patterns in this clade.

Compared to studies of dental load-resisting ability, we know much less about how the teeth act to reduce masticatory stresses (i.e., act efficiently) in platyrrhines. The effective distribution of dental material for fracturing food items can impact loads experienced in the jaws by reducing both muscular and reaction forces. Outside of platyrrhines, studies of tooth crest sharpness have been important in understanding the functional principles guiding variation in tooth form in mammals (e.g., Rensberger, 1973; Strait, 1993; Popowics and Fortelius, 1997; Evans et al., 2005; Lucas, 2004; Ang et al., 2006).

Marmoset incisors represent one case among platyrrhines where efficiency has been identified as a factor in the evolution of dental form as it relates to their derived tree-gouging behavior (Fig. 7). The thickened labial and reduced lingual enamel of marmoset incisors is hypothesized to offer a mechanism for maintaining sharpness through differential wear of dentine and enamel (Rosenberger, 1978, 1992). We briefly consider this example to highlight the potential impact of dental efficiency on helping to understand masticatory loads during feeding. 


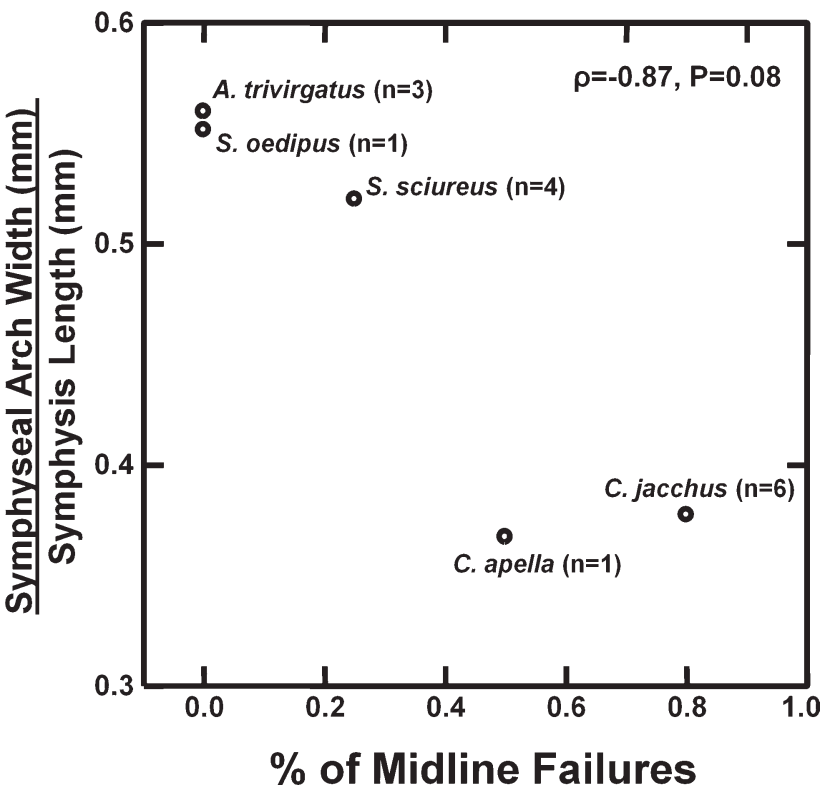

Fig. 5. Plot of the percentage of midline failures during in vitro lateral transverse bending versus relative symphyseal shape among platyrrhines (see Hogg et al., 2011 for loading details). Symphyseal shape is measured as the mediolateral width of the symphysis near its lingual border divided by symphysis length (primarily an AP distance). The negative Spearman's rank correlation $(\rho)$ suggests that more "v-shaped" symphyses (i.e., smaller ratios) tend to break along the midline. This result may indicate a tendency for symphyseal shape in platyrrhines to dictate patterns of failure during in vitro loading. The single $C$. apella individual failed superiorly at the midline, but the crack propagated inferiorly to below the canine. This was scored as 0.5 , but should be considered preliminary pending additional data for this species. (Abbreviations: A. trivirgatus = Aotus trivirgatus; S. oedipus = Saguinus oedipus; $S$. sciureus = Saimiri sciureus; $C$. apella = Cebus apella; . jacchus = Callithrix jacchus).

The marmoset incisor is best modeled as a sharp wedge when gouging to remove pieces of bark (to stimulate exudate flow for later consumption) (Fig. 7). Separating a piece of bark is a complicated process involving initial indentation, fracture, and propagation of the initial crack (Lucas, 2004; Atkins, 2009). Hypotheses about incisor tip sharpness immediately apply to the indentation of the bark. The impact of sharpness on indentation will depend on the material properties of the substrate (i.e., bark), but the basic concept is that all else being equal a sharper incisor tip will act to reduce the relative force needed to indent (up to a threshold) (Meehan and Burns, 2007; Atkins, 2009). While the sharpness of a cutting tip is measured in several ways (Atkins, 2009), we compare the tip radius of curvature between five common marmosets and five saddle-back tamarins (see Hogg et al., 2011 for sample details). The radius of curvature in marmosets $(0.119 \mathrm{~mm})$ is significantly smaller than in tamarins $(0.172 \mathrm{~mm}$ ) (ANOVA, $F=10.5, P=$ 0.012) (Fig. 8), while both have sharpness values comparable to similar-sized mammals (Popowics and Fortelius, 1997; Evans, 2005). The significant difference between these two species supports the hypothesis that enamel modifications in marmosets help maintain tip sharpness. By focusing the bite force over relatively smaller cusp tips (i.e., elevating stresses on the bark), loads may be reduced throughout the jaw during this initial phase of the gouge.

Atkins (2009) argues that there is little benefit of dental cusps becoming sharper than the critical distance for crack opening displacement $(\delta)$ of a dietary substrate. We can estimate the average $\delta$ for barks gouged by common marmosets by dividing average toughness $(R)(1.92 \mathrm{~kJ} /$ $\mathrm{m}^{2}$ ) by yield strength $\left(\sigma_{\mathrm{y}}\right)(6.9 \mathrm{MPa})$ (where $\sigma_{\mathrm{y}}$ is estimated as $3 \times$ the average hardness of $2.3 \mathrm{MPa}$; Kendall, 2001) using mechanical property data from gouged barks (Vinyard et al., 2009; unpubl. data). The average $\delta$ of $0.278 \mathrm{~mm}$ for these barks approximates the sharpness of callitrichine teeth (i.e., $2 \times$ radius of curvature) suggesting that marmosets may have reached a beneficial sharpness threshold for gouging. Alternatively if a bark tends to collapse on itself during indentation (i.e., it exhibits a Poisson's ratio approaching 0 due to the underlying organization of cells), then the estimate of yield strength as $3 \times$ hardness is too large. Subsequently, $\delta$ would increase (up to $0.83 \mathrm{~mm}$ for a bark that collapses completely; Lucas, 2004) and may indicate that the increased tip width of marmoset incisors compared to tamarins (Hogg et al., 2011) helps to create the critical distance for propagating a crack through barks during gouging.

At some depth during the indentation, a flaw in the bark will develop into a crack as the incisors wedge deeper into the bark. The largest bite forces during a gouge are likely associated with this phase of the gouge as sufficient strain energy is required to develop a free running crack ahead of the teeth (Vincent et al., 1991; Atkins, 2009). In general, a relatively wider incisal tip will tend to elevate bite forces in elastic materials. The benefit of the wider tip is that it decreases the depth at which a crack propagates by widening the distance between sides of the bark, increasing stored strain energy and attaining the critical distance for crack propagation $(\delta)$ more quickly. Ang et al. (2006) recently modeled the strain energy release rate $(G)$ for an incisor penetrating a substrate as:

$$
G=\frac{F}{b}\left[1-\frac{\mu}{\cos \left(\frac{\alpha}{2}\right)\left[\sin \left(\frac{\alpha}{2}\right)+\mu \cos \left(\frac{\alpha}{2}\right)\right]}\right]
$$

where $F=$ bite force (i.e., normal force), $b=$ incisor contact width, $\mu=$ the friction coefficient, and $\alpha=$ the included angle of the incisor (see also Williams, 1998). We can apply average values from in vivo recordings of bite forces during gouging and estimates of friction between marmoset teeth and barks to estimate how $G$ changes as a function of the incisor included angle between marmosets and tamarins. We estimated included angles at $1 \mathrm{~mm}$ from the incisor tip (marmoset $\bar{x}=74$ degree, tamarin $\bar{x}=57$ degree) and for the entire crown (marmoset $\bar{x}=32$ degree, tamarin $\bar{x}=28$ degree) using data by Hogg et al. (2011). Figure 9 shows that across the range of observed friction coefficients for gouged trees $(\mu=0.2-0.65$; Vinyard, unpubl. data), marmosets have slightly higher strain energy release rates $(G)$ for the incisal tip at low friction, but this pattern reverses at higher friction coefficients. Marmosets maintain slightly higher $G$ estimates relative to the included angle for the crown (Fig. 9). In both cases, the included angle has limited impact on variation in $G$ estimates, particularly when compared to the effect of 
Callithrix

\section{V-shaped symphysis}
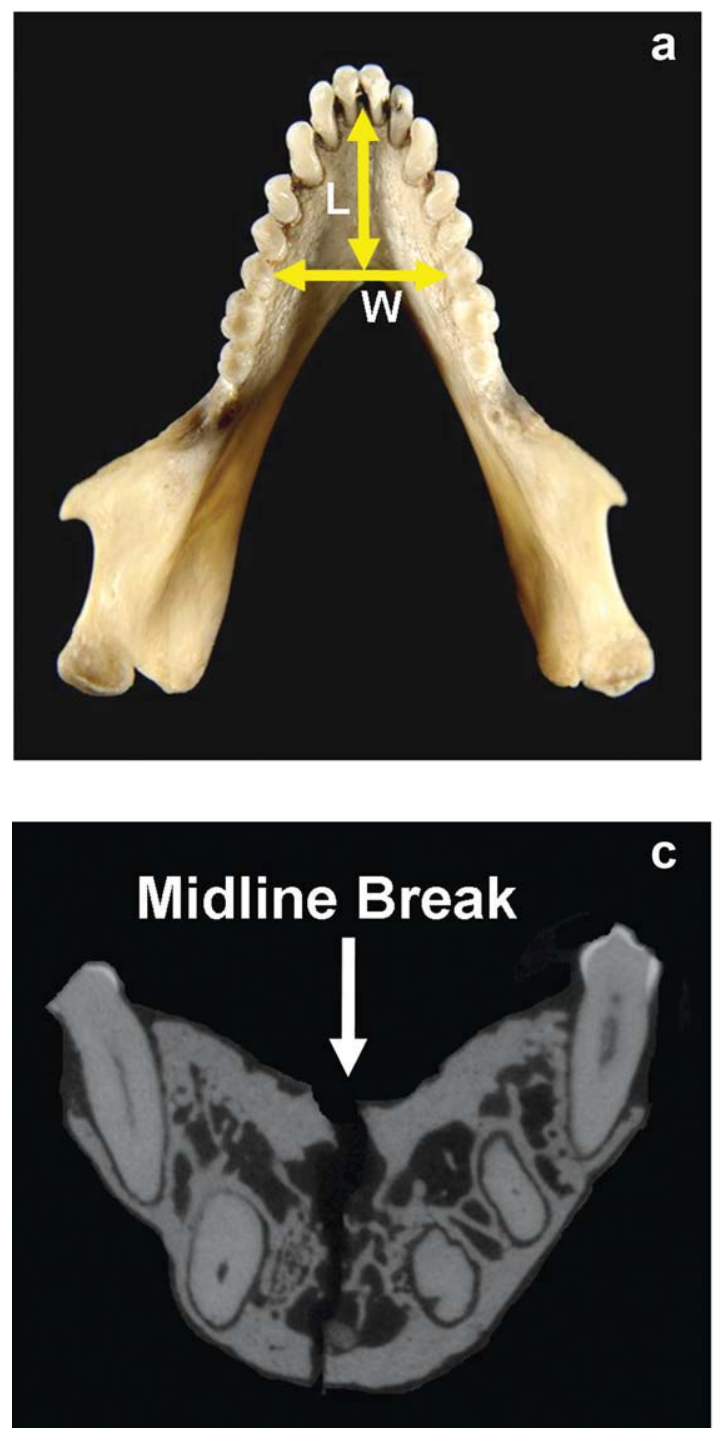

Fig. 6. The relationship between symphyseal shape and breakage patterns in platyrrhines. Superior-view photographs of (a) a v-shaped symphysis (Callithrix) and (b) a u-shaped symphysis (Aotus). The yellow arrows demonstrate symphyseal arch width $(W)$ and symphysis length $(L)$ shown in Fig. 5. $\mu$ CT cross-sections of (c) a Callithrix sym-

friction. This result suggests that any improvements in energy release rate based on marmoset incisor angulation are relatively small and may not markedly impact loads during a single gouge. ${ }^{1}$ A cumulative effect of slightly

\footnotetext{
${ }^{1}$ These results model the wedging of an elastic substrate. The introduction of plastic deformation in the substrate, which may characterize some barks (e.g., Gibson and Ashby, 1997; Xu et al., 1997), can significantly affect these estimates (Williams, et al., 1998; Ang et al., 2006; Atkins, 2009). Further work is warranted in modeling the effect of incisal wedge angle during the splitting of substrates that include a plastic deformation phase.
}

\section{Aotus \\ U-shaped symphysis}
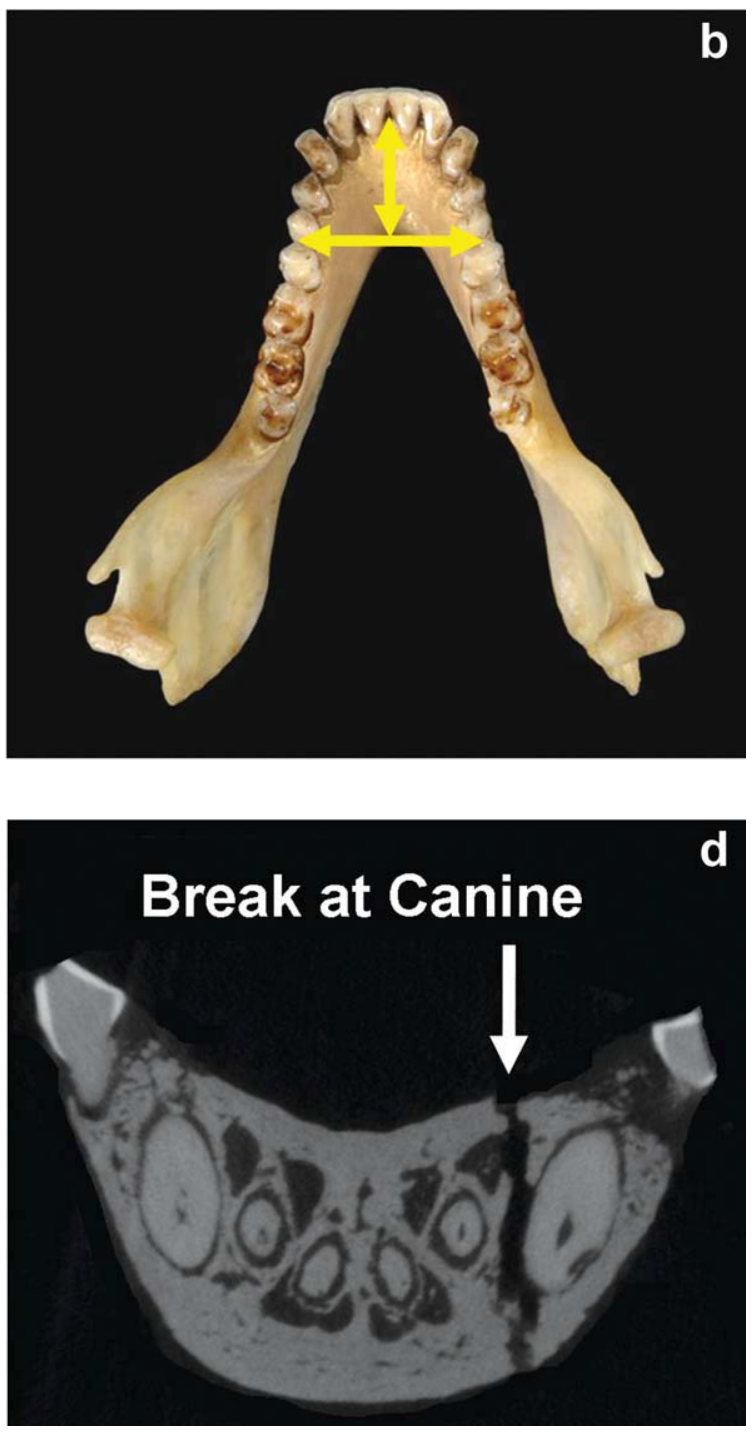

physis that broke in the midline during loading in wishboning and (d) an Aotus symphysis that broke along the medial edge of the canine root (white arrows). Resolution of $\mu \mathrm{CT}$ slices $=20.5 \mu \mathrm{m}$. Photographs of jaws $(a, b)$ are reproduced under Creative Commons License: Copyright to Phil Myers, Museum of Zoology, University of Michigan.

elevated strain energy release rates $(G)$, however, remains possible.

Based on these results, we hypothesize that the sharpness of the incisors, the width of the incisal tip, and the included angle of the incisor crown may increase efficiency and reduce the loads experienced by the marmoset facial skeleton during gouging. While sharpness may reduce indenting forces, the wider tip may actually increase forces during the initiation of a stable crack. The ability to quickly generate and propagate a stable crack (by reaching $\delta$ sooner) may reduce the net forces required in separating a piece of bark (see Vincent et al., 
1991). To benefit from this design, marmosets should attempt to propagate cracks through large excursions during gouging. Both behavioral and morphological data

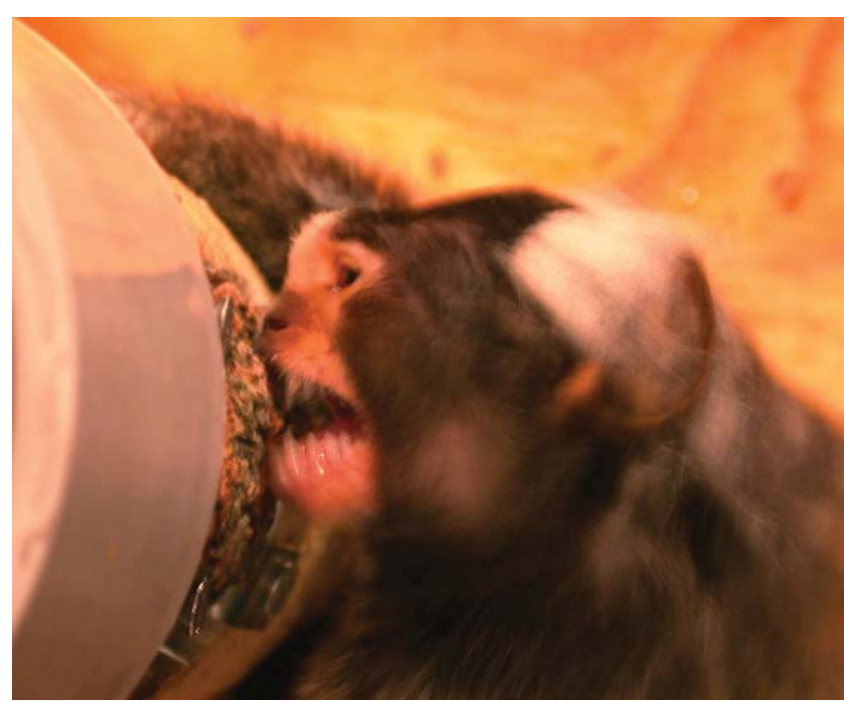

Fig. 7. Photograph of a captive common marmoset (Callithrix jacchus) gouging a simulated tree substrate (i.e., section of sweetgum tree affixed to force platform) in a laboratory setting. A gouge proceeds by the animal anchoring the upper dentition in the tree substrate and moving the lower anterior teeth through the substrate to remove a segment as shown in the figure. support this hypothesis by demonstrating that marmosets use large jaw gapes during gouging and have a masticatory apparatus that facilitates these large excursions during this behavior (Vinyard et al., 2003, 2009; Taylor et al., 2009).

\section{Jaw-Muscle Fiber Architecture}

Muscle fiber architecture considers the arrangement of muscle fibers relative to the force-generating axis of the muscle (Gans and Bock, 1965). Holding other factors constant, muscles with long, parallel fibers tend to exhibit increased excursion while muscles with shorter, more pinnate fibers can pack more fibers together, increasing the physiologic cross-sectional area (PCSA) and force-producing capacity. Recent comparative investigations of jaw-muscle fiber architecture in platyrrhines have yielded important insights into how jaw-muscle architecture relates to masticatory apparatus form and load resistance during feeding in this clade (Taylor et al., 2009; Taylor and Vinyard, 2009).

In vivo analyses suggest that marmosets use relatively large jaw gapes, but not relatively large bite forces, during tree gouging (Vinyard et al., 2009). Metric comparisons match these in vivo data by showing that marmosets do not have relatively robust jaws for resisting significant bite forces compared to non-gouging platyrrhines (Vinyard et al., 2003; Vinyard and Ryan, 2006; Ryan et al., 2010). Taylor et al. analyzed the fiber architecture of the jaw-closing muscles in tree-gouging pygmy (Cebuella pygmaea) and common (Callithrix jacchus)

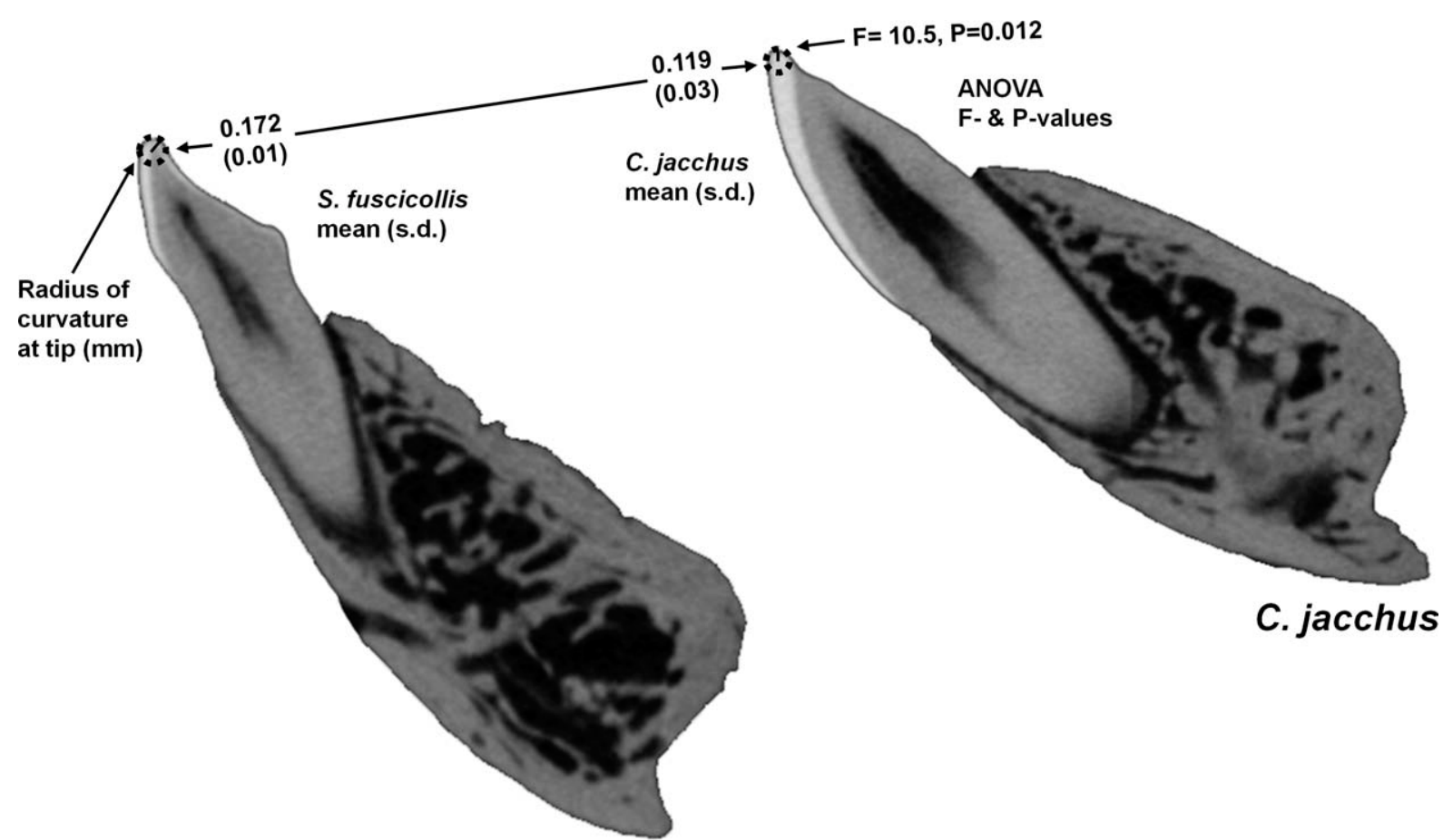

\section{S. fuscicollis}

Fig. 8. Comparison of tip radius of curvature between common marmosets (Callithrix jacchus, $\mathrm{N}=5$ ) and saddle-back tamarins (Saguinus fuscicollis, $N=5$ ). Curvature was measured as the radius of a circle fit to the cusp tip of the lower, central incisor of each individual. Central incisor segments were obtained from high-resolution $\mu \mathrm{CT}$ scans of jaws (see Ryan et al., 2010; Hogg et al., 2011 for details of $\mu \mathrm{CT}$ scanning). Marmosets maintain a significantly sharper cusp tip, based on an ANOVA comparing the cusp radius of curvature ( $F=$ $10.5, P=0.012)$ 


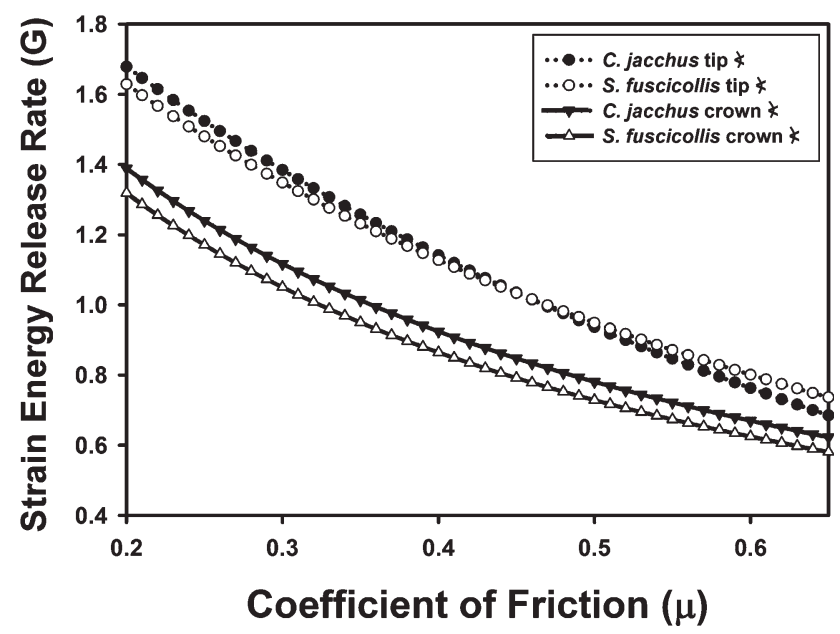

Fig. 9. Plot of estimated strain energy release rate $(G)$ in common marmosets (C. jacchus, closed symbols) and saddle-back tamarins (S. fuscicollis, open symbols) across a range of friction coefficients $(\mu)$ for barks gouged by marmosets ( $\mu=0.2-0.65$; Vinyard, unpubl. data). Estimates of $G$ are based on Eq. (2) in Ang et al. (2006). Bite force = $10 \mathrm{~N}$ (Vinyard, unpub data) and incisor contact width $(b)=4 \mathrm{~mm}$. Coefficients of friction were calculated by dragging marmoset teeth across gouged bark samples using a Lucas-Darvell HKU tester (see Lucas, 2004). Included angles were measured at $1 \mathrm{~mm}$ from the incisor tip (marmoset $\bar{x}=74$ degree, tamarin $\bar{x}=57$ degree) and for the entire crown (marmoset $\bar{x}=32$ degree, tamarin $\bar{x}=28$ degree) using data from Hogg et al. (2011).

marmosets and observed that tree gougers have relatively longer masseter and temporalis fibers compared to non-gouging tamarins (Taylor and Vinyard, 2004, 2008; Eng et al., 2009; Taylor et al., 2009). Because of the architectural tradeoff between fiber length and PCSA, tree gougers have relatively smaller PCSAs as the increase in jaw-muscle excursion comes at some expense to maximal force production. Thus, jaw-muscle architecture in tree-gouging marmosets fits the prediction of relatively long fibers to facilitate relatively wide jaw gapes. Moreover, marmoset jaw-muscles are not geared for producing relatively large maximal bite forces during gouging, linking the lack of jaw robusticity to a comparatively weaker set of jaw muscles.

In contrast to marmosets, tufted capuchins (Cebus apella) have a masticatory apparatus that has been functionally and adaptively linked to generating and dissipating relatively large bite forces during feeding on resistant food objects (Kinzey, 1974; Kay, 1981; Cole, 1992; Daegling, 1992; Masterson, 1997; Wright, 2005). Taylor and Vinyard (2009) found that $C$. apella has a masseter and temporalis architecture that favors the production of relatively large maximum muscle forces compared to untufted capuchins that feed on less-resistant foods. Importantly, the capacity to generate relatively higher muscle force is primarily a function of increased jaw-muscle mass, with little difference in fiber lengths or pinnation angles among capuchins. These findings suggest that $C$. apella can generate relatively large muscle forces without markedly compromising gape. This result agrees with behavioral observations that $C$. apella process large food items with the cheek teeth (Izawa, 1979; Terborgh, 1983; Wright, 2004; Norconk et al., 2009). Collectively, these architectural analyses of marmoset and capuchin jaw muscles emphasize the diverse functional strategies used by these two platyrrhine groups during feeding.

The results of these two studies demonstrate an integration of musculoskeletal form suggesting that further analyses of platyrrhine jaw-muscle architecture may help us better understand the loading history of the masticatory apparatus in this clade. As a preliminary assessment, we consider the relative force producing capacity (PCSA) of the superficial masseter and temporalis across 11 platyrrhine species (Taylor et al., 2009; Taylor and Vinyard, 2009; Taylor, unpubl. data). Figure 10 a suggests that relative PCSA may vary with size $(\mathrm{r}=$ $0.52, P=0.1)$ keeping in mind that PCSA $\left(\mathrm{mm}^{2}\right) /$ jaw length $(\mathrm{mm})$ retains the effect of scale (i.e., the estimate is not dimensionless). In addition to a potential sizerelated trend, hard object feeding taxa, such as $C$. apella and $P$. pithecia, exhibit relatively large PCSA estimates. In contrast, the more folivorous $A$. seniculus possesses a relatively reduced jaw-muscle PCSA, suggesting that large body size rather than relatively enhanced jawmuscle force production is key to the functional morphology of feeding in howlers. At smaller body sizes, tree gouging marmosets exhibit relatively reduced PCSA compared to non-gouging taxa (Taylor et al., 2009) (Fig. 10a).

The significant correlation $(\mathrm{r}=0.76, P=0.01)$ between relative PCSA and a robusticity index computed from 10 measures of the jaws and teeth (Norconk et al., 2009) suggests that variation in jaw-muscle architecture tracks variation in the bony masticatory apparatus across platyrrhines (Fig. 10b). Hard-object feeding platyrrhines tend to possess both relatively robust jaws and relatively large PCSA, while A. seniculus exhibits both relatively reduced skeletal robusticity and jaw-muscle PCSA. This preliminary association between musculoskeletal measures across platyrrhines suggests that these two morphological systems are evolving together in platyrrhines as they both play integral roles in feeding performance (Vinyard and Taylor, 2010). Future work on jaw-muscle architecture exploring the details of these relationships will be important for understanding the functional morphology of the platyrrhine masticatory apparatus.

\section{MASTICATORY BIOMECHANICS IN AN ECOLOGICAL SETTING}

Characterizing natural feeding behaviors is essential to understanding the functional morphology of feeding in any species. In platyrrhines, feeding ecology research that is directly pertinent to masticatory apparatus form has focused on describing diets (e.g., Ayres, 1986; Strier, 1991; Norconk 1996; Palacios et al., 1997; Peetz, 2001; Porter, 2001; Di Fiore, 2004; Wallace, 2005; Norconk et al., 2009) and their mechanical properties (e.g., Wright, 2005; Teaford et al., 2006; Vinyard et al., 2009). For example, Norconk et al. (2009) compared jaw morphologies across platyrrhines to both the mechanical and nutritive properties of their diets. Neither dietary variable was strongly associated with morphological variation across New World monkeys. Unfortunately, the small sample sizes, particularly for the mechanical property data, preclude any definitive statements regarding these potential relationships. 


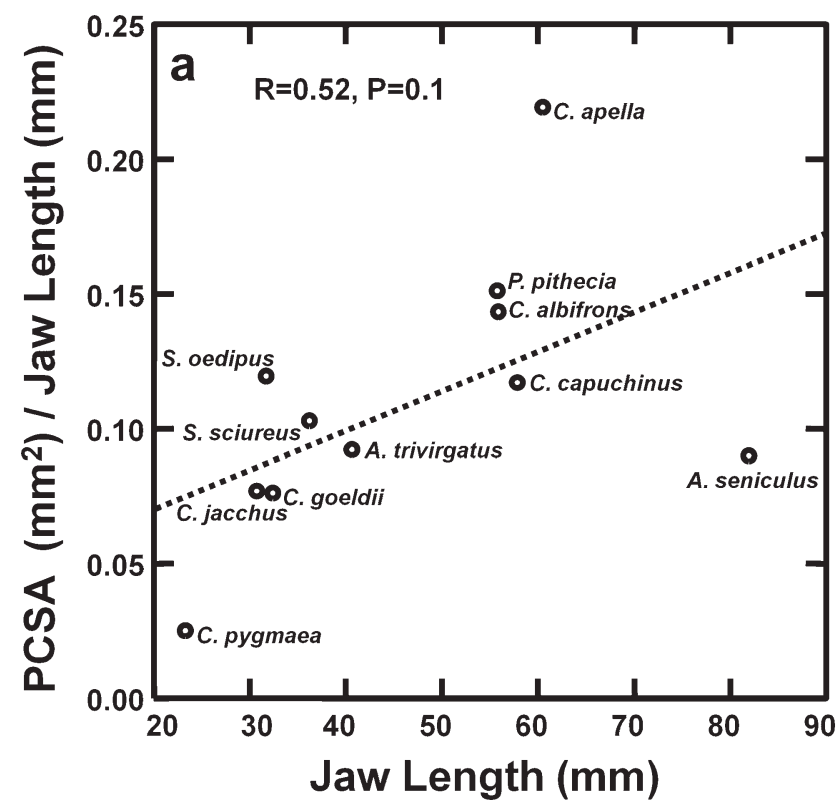

Fig. 10. Plot of combined superficial masseter and temporalis physiologic cross-sectional area (PCSA) versus (a) jaw length and a (b) mandibular robusticity index in 11 platyrrhine species. PCSA was estimated following methods outlined by Taylor et al. (2009) and Taylor and Vinyard (2009). Whenever possible, PCSA estimates are based on fiber lengths normalized to a resting sarcomere length, but when normalization was not possible, only individuals fixed with incisors in tipto-tip occlusion were included. While admittedly not ideal, we anticipate that interspecific variation across this range of species will more than outpace potential variation due to these two methods of adjust-

Beyond improving our assessments of natural dietary properties, ecological research provides an opportunity to assess feeding behaviors in a realistic evolutionary setting. While numerous descriptions of platyrrhine feeding exist, we lack significant details on the ecological physiology_or environmentally relevant physiology-of feeding in platyrrhines that would allow us to identify how specific physiological processes help an organism cope in a given environment (e.g., Bartholomew, 1987). By conducting in vivo physiology studies separate from feeding ecology research, we are forced to assume that physiological data in the lab are comparable to feeding behaviors typical of free-ranging animals (Williams et al., 2008b; Thompson et al., 2011). The lack of integration between physiology and ecology likely limits our ability to advance adaptive hypotheses linking craniodental morphology, function, and feeding behaviors.

As a first attempt to link in vivo laboratory and fieldbased ecological research, we are recording jaw-muscle activity during feeding in free-ranging mantled howling monkeys (Alouatta palliata) (Williams et al., 2008b) (Fig. 11). The telemetered EMG data from the jaw muscles (Fig. 12) allows us to measure several ecologically relevant variables, such as the percentage of a feeding bout that the muscles are active (i.e., duty factors), the percentage of feeding time spent masticating foods and the daily number of loads experienced by the bony masticatory apparatus. We can also relate muscle recruitment to other ecologically relevant variables such as ranging behaviors, dental wear rates, and food mate-

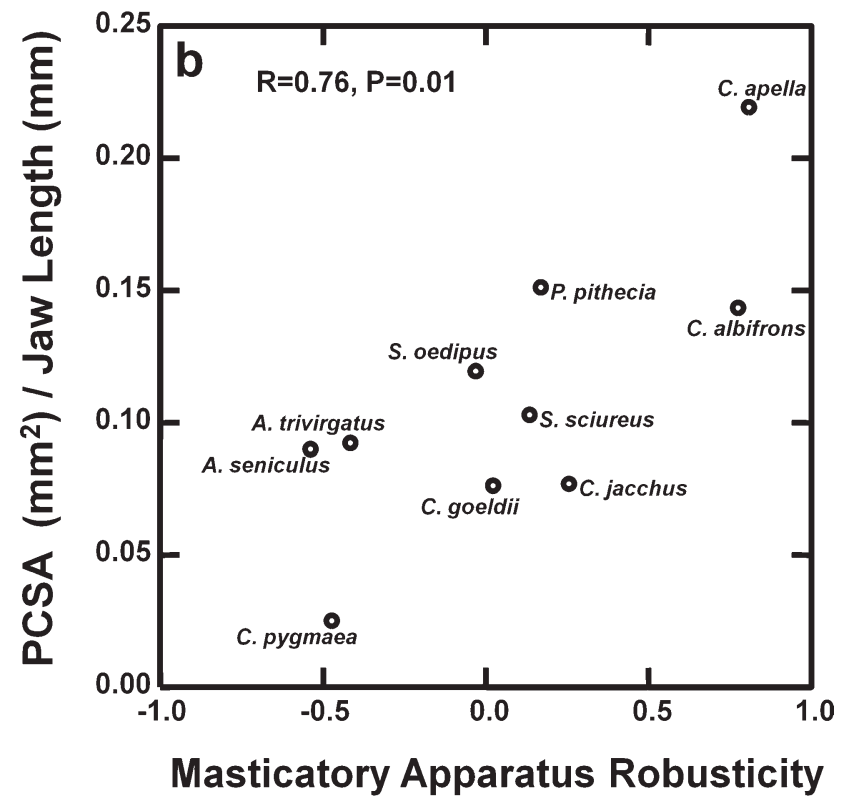

ing for variation in fiber length fixation. Jaw length was measured as the midline distance from the mandibular condyles to infradentale. The mandibular robusticity index is taken from Norconk et al. (2009) and averages $z$-scores from 10 relative measures of the masticatory apparatus related to bite force production, load resistance and dental function. (Abbreviations: $C$. apella $=$ Cebus apella; $C$. albifrons $=$ Cebus albifrons; $P$. pithecia = Pithecia pithecia; $S$. sciureus = Saimiri sciureus; C. jacchus = Callithrix jacchus; $S$. oedipus = Saguinus oedipus; C. goeldii; Callimico goeldii; $A$. trivirgatus = Aotus trivirgatus; $A$. seniculus = Alouatta seniculus; C. pygmaea = Cebuella pygmaea).

rial properties. For example, in an initial comparison of jaw-muscle EMG activity and food toughness we see little association between these variables over a two-day recording period (Fig. 13). While highly preliminary, the lack of association may indicate that food material properties are not necessarily closely related to the normal physiological parameters of mastication on a day-to-day basis. A speculative implication of this result is that many of the events that ultimately determine specieslevel differences in form and behavior might occur as temporally discrete episodes (potentially separated by years) linked to dietary extremes in an environment (e.g., Boag and Grant, 1981; Grant and Grant, 2002). For example, this episodic evolutionary pattern could perhaps lie at the root of evolutionary "paradoxes" involving taxa, like Paranthropus boisei (Grine et al., 2010; Strait et al., 2009; Ungar et al., 2008), seemingly adapted to a wide range of activities, but pursuing some of them infrequently at best (Robinson and Wilson, 1998; Marshall and Wrangham, 2007). If true, then long-term feeding studies in primates will be more likely to capture these evolutionarily significant events.

From a physiological perspective, these data support the hypothesis that howlers will behaviorally modulate diets by choosing foods and bolus sizes that facilitate rhythmic mastication within a specific physiological range (see Reed and Ross, 2010). We can speculate that in howlers this physiological range emphasizes efficient processing related to their large number of daily chewing cycles. We can further hypothesize that an emphasis 


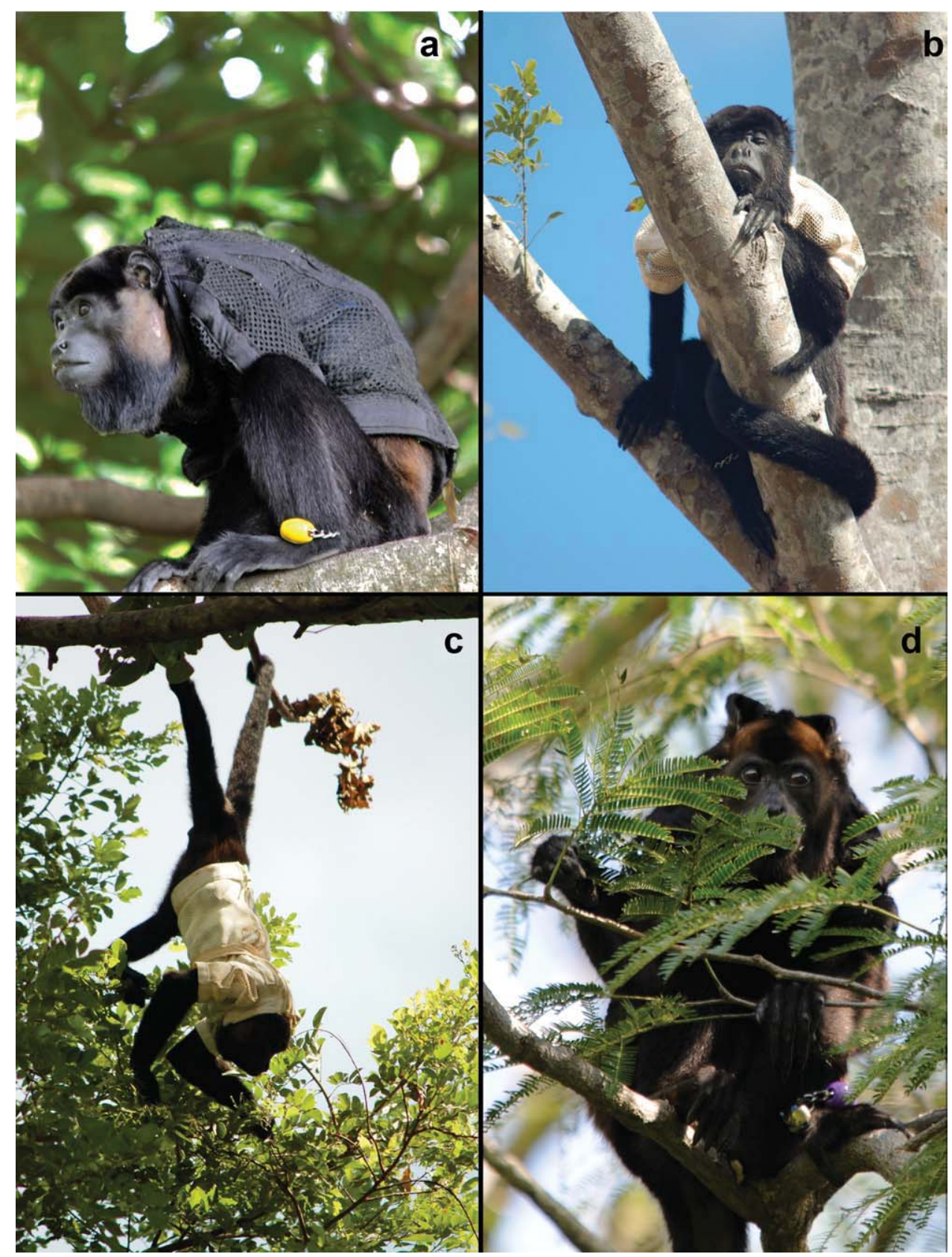

Fig. 11. Photographs of free-ranging mantled howling monkeys (Alouatta palliata) wearing an EMG telemetry unit (and associated jacket) in their natural habitat at La Pacifica, Costa Rica. Individual photos demonstrate animals continuing their normal daily activities including (a) sitting postures, (b) resting, (c) foraging and locomotion, and (d) feeding behaviors while wearing the telemetry unit.

on efficient processing may differ from hard-object feeding platyrrhines that may need to prioritize masticatory strength (i.e., bite force and load-resistance ability) as they periodically generate large bite forces, relative to their maximum capabilities, during feeding. The implication of these differing physiological strategies for musculoskeletal form may go beyond the readily observed differences in morphology and predicted functional capacity. Musculoskeletal morphologies may be adapted to fundamentally different physiological parameters between these dietary groups of New World monkeys. This potential difference in physiological strategies for effectively breaking down their respective diets may also help explain why the howler masticatory apparatus does not appear particularly robust among platyrrhines (Norconk et al., 2009). Furthermore, if this initial result is supported by additional eco-physiological data, then morphologists studying masticatory form may need to look beyond assessing maximal abilities (i.e., most assessments of musculoskeletal form) and separately 
Feeding bout: 3360 seconds

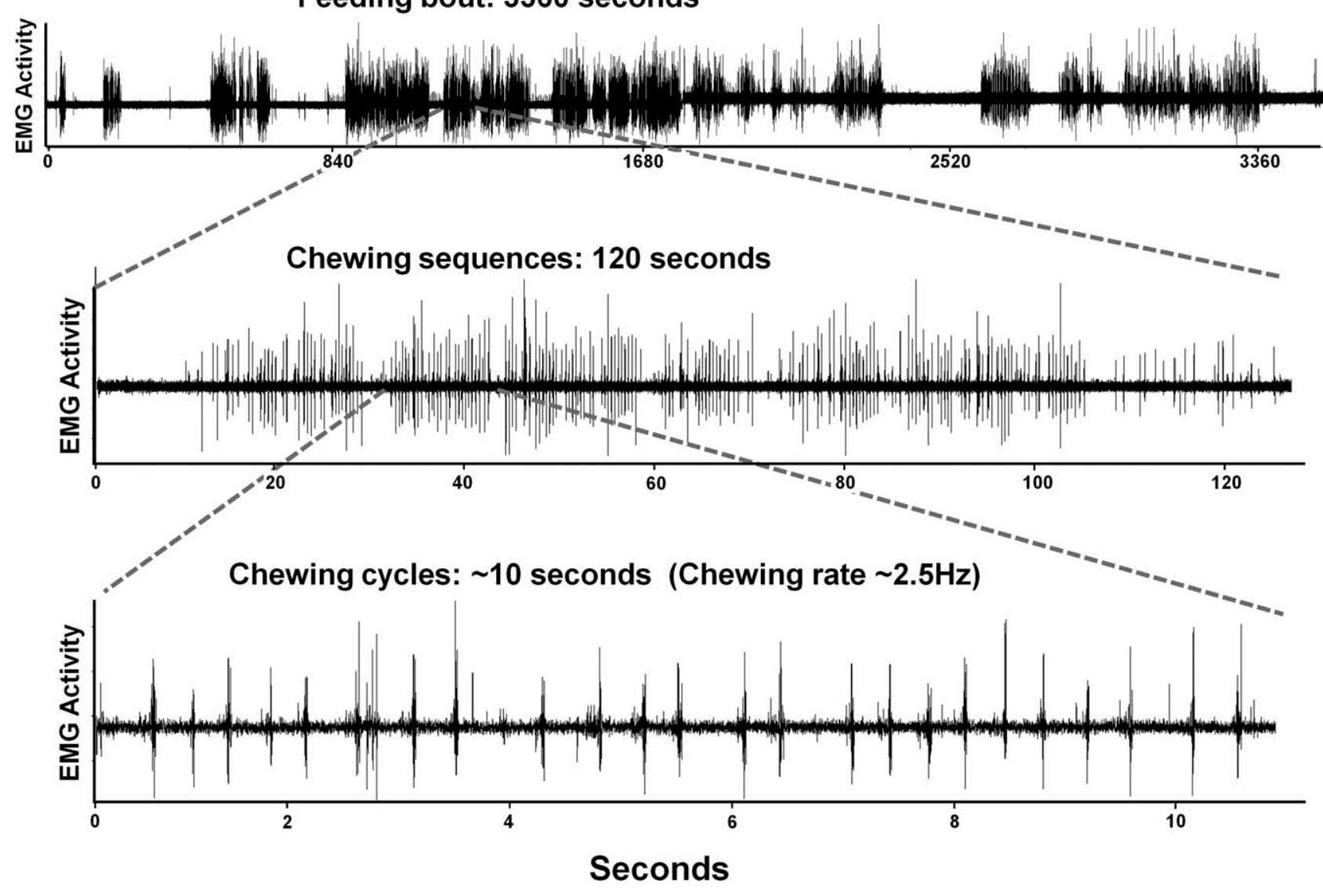

Fig. 12. Plot of electromyographic (EMG) activity from the rightside deep masseter of a female mantled howler (Alouatta palliata) during a single feeding bout in La Pacifica, Costa Rica. The feeding bout consisted of consuming Lysiloma sp. leaves and lasted approximately
56 min. This individual's jaw muscles were active about $60 \%$ of the feeding bout. This percentage appears to vary markedly, however, across animals, foods and days. EMG implantation and recording procedures are outlined in Williams et al. (2008b). consider the effects of hard-object versus tough-object feeding (e.g., peak loads vs. repetitive loads) on bone and muscle. For example, recent approaches describing how dietary plasticity impacts skull growth can provide novel insights into the lifetime effects of dietary variation on skull form (Ravosa et al., 2007; Menegaz et al., 2009). Continued development of this physiological ecology approach to studying primate feeding will help us to both address these specific issues in bone and muscle physiology and ultimately build our understanding of platyrrhine masticatory apparatus loading and evolution.

\section{SUMMARY}

We briefly reviewed several ongoing projects aimed at exploring the evolutionary and functional morphology of the platyrrhine masticatory apparatus. Several of the projects highlight current gaps in our knowledge and call for new data. The need for in vivo data documenting loading regimes in the platyrrhine skull during mastication is clear and these data simply need to be collected. Our preliminary in vivo mandibular strains from capuchins suggest that Old World monkeys may not be an ideal model of jaw loading patterns for platyrrhines.
Some of the projects we discussed call for a broader examination of morphology incorporating new techniques and concepts. Technological advances should improve accuracy in quantifying morphology and provide new insights into form-function relationships. Even though we did not discuss Finite Element Analyses (FEA), this approach can help test functional hypotheses in platyrrhines not readily addressed by more traditional methods (e.g., Ross et al., 2010; Dumont et al., 2011). Finally, we reviewed several projects that integrate previously distinct research traditions in studying platyrrhine feeding biology. Whether these are studies of dental form incorporating material science engineering, analyses linking jaw muscles with their underlying skeletal form, or efforts to collect in vivo physiological data during feeding in natural habitats, we argue that integration of approaches will offer the greatest opportunity for advancing our knowledge of platyrrhine feeding biology. We understand that metric analyses of form will dominate functional morphology studies of the platyrrhine masticatory apparatus because of logistical limitations. Our morphometric analyses, however, would benefit from stronger links to physiology and feeding behaviors given that these data tell us how morphology behaves during feeding. The diversity in feeding across 


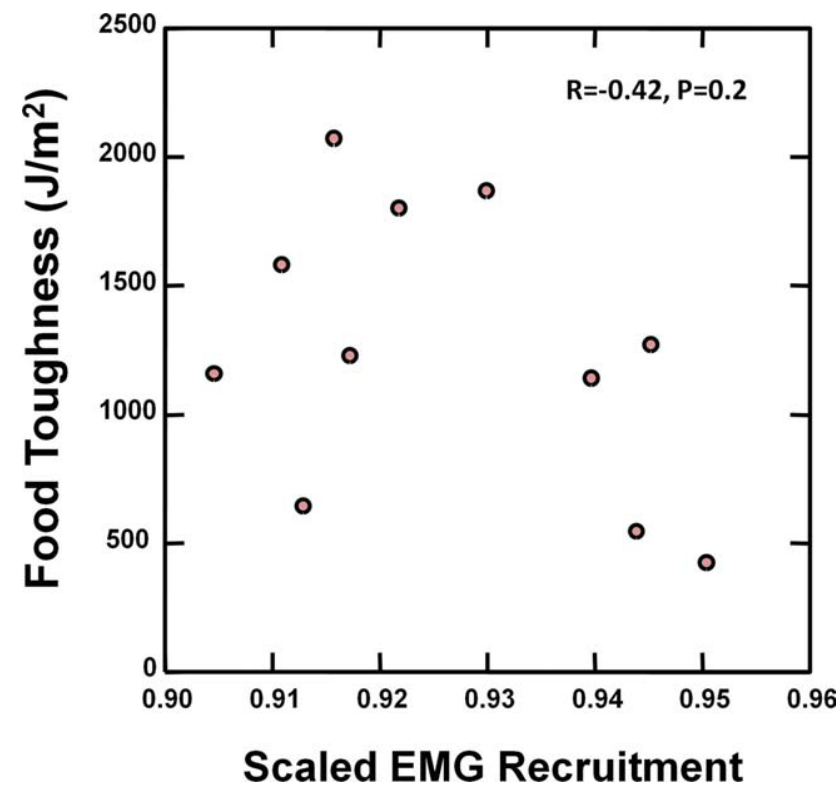

Fig. 13. Plot of scaled EMG recruitment versus food toughness for a single female howler ( $A$. palliata) from 11 separate feeding bouts over a two-day period. The product-moment correlation $(r=-0.42, P$ $=0.2$ ) suggests that relative EMG recruitment levels for the jaw muscles are not correlated with food toughness over this two-day period. This result suggests that animals may behaviorally modulate food intake to maintain feeding activities within a specific physiological range. EMG levels are scaled to the maximum observed value for an electrode during the two-day period (i.e., $\leq 1$ ). We used the scissors test on a Lucas-Darvell HKU tester to estimate food toughness for dropped or similar food items (i.e., leaves) (see Lucas, 2004; Teaford et al., 2006).

platyrrhines offers researchers an excellent natural dietary experiment for understanding how primate skulls are tuned to their diets. New data and new links across research traditions will provide a clearer and more informed view of the loading profiles in the masticatory apparatus of New World monkeys and will help us to better understand how feeding shaped the platyrrhine face.

\section{ACKNOWLEDGEMENTS}

Authors thank Alfie Rosenberger for the invitation to participate in this special issue of the Anatomical Record. The authors thank A. Doherty, C. Eng, E. Han, K. Jones, N. Robl, C. Rose, and C. Thompson for assistance in data collection. Authors would like to acknowledge several museums, institutes, and primate centers (AMNH, FMNH, HMB, MNHN, NEPRC, NHM-London, SMBRR, UTCT-UTexas, USNM, UZH, WPRC) for access to, supply of and/or scanning of primate musculoskeletal materials as indicated in original publications. The veterinary staff at NEOUCOM provided animal care for capuchins.

\section{LITERATURE CITED}

Agrawal KR, Lucas PW, Bruce IC. 2000. The effects of food fragmentation index on mandibular closing angle in human mastication. Arch Oral Biol 45:577-584.
Agrawal KR, Lucas PW, Bruce IC, Prinz JF. 1998. Food properties that influence neuromuscular activity during human mastication. J Dent Res 77:1931-1938.

Ahlgren J. 1966. Mechanism of mastication. Acta Odont Scand 24:1-109.

Anapol F, Lee S. 1994. Morphological adaptations to diet in platyrrhine primates. Am J Phys Anthropol 94:239-261.

Ang KY, Lucas PW, Tan HTW. 2006. Incisal orientation and biting efficiency. J Hum Evol 50:663-672.

Armfield BA, Vinyard CJ. 2010. An interspecific analysis of relative jaw-joint height in primates. Am J Phys Anthropol 142:519-530.

Atkins T. 2009. The science and engineering of cutting: the mechanics and processes of separating, scratching and puncturing biomaterials, metals and non-metals. New York: ButterworthHeinemann.

Ayres JM. 1986. Uakaris and Amazonian flooded forest. Cambridge: University of Cambridge.

Bartholomew GA. 1987. Interspecific comparison as a tool for ecological physiologists. In: Feder ME, Bennett AF, Burggren WW, Huey RB, editors. New directions in ecological physiology. Cambridge: Cambridge University Press. p 11-35.

Boag PT, Grant PR. 1981. Intense natural selection in a population of Darwin's finches (Geospizinae) in the Galapagos. Science 214:82-85.

Bouvier M. 1986a. A biomechanical analysis of mandibular scaling in Old World monkeys. Am J Phys Anthropol 69:473-482.

Bouvier M. 1986b. Biomechanical scaling of mandibular dimension in New World Monkeys. Int J Primatol 7:551-567.

Bouvier M, Hylander WL. 1982. The effect of dietary consistency on morphology of the mandibular condylar cartilage in young macaques (Macaca mulatta). In: Dixon AD, Sarnat BG, editors. Factors and mechanisms influencing bone growth. New York: Alan R. Liss, Inc. p 569-579.

Campbell CJ, Fuentes A, MacKinnon KC, Panger M, Bearder SK. 2007. Primates in perspective. New York: Oxford University Press.

Chai H, Lee JJW, Constantino PJ, Lucas PW, Lawn BR. 2009. Remarkable resilience of teeth. Proc Natl Acad Sci USA 106:72897293.

Cole TM. 1992. Postnatal heterochrony of the masticatory apparatus in Cebus apella and Cebus albifrons. J Hum Evol 23:253-282.

Conroy GC. 1990. Primate evolution. New York: W.W. Norton \& Company.

Corruccini RS, Beecher RM. 1982. Occlusal variation related to soft diet in a nonhuman primate. Science 218:74-76.

Corruccini RS, Beecher RM. 1984. Occlusofacial morphological integration lowered in baboons raised on soft diet. J Craniofac Genet Develop Biol 4:135-142.

Daegling DJ. 1989. Biomechanics of cross-sectional size and shape in the hominoid mandibular corpus. Am J Phys Anthropol 80:91-106.

Daegling DJ. 1993. The relationship of in vivo bone strain to mandibular corpus morphology in (Macaca fascicularis). J Hum Evol 25:247-269.

Daegling DJ. 1992. Mandibular morphology and diet in the genus Cebus. Int J Primatol 13:545-570.

Daegling DJ. 2001. Biomechanical scaling of the hominoid mandibular symphysis. J Morphol 250:12-23.

Daegling DJ. 2002. Bone geometry in cercopithecoid mandibles. Arch Oral Biol 47:315-325.

Daegling DJ. 2007. Morphometric estimation of torsional stiffness and strength in primate mandibles. Am J Phys Anthropol 132:261-266.

Daegling DJ, Granatosky MC, McGraw WS, Rapoff AJ. 2011a. Reduced stiffness of alveolar bone in the colobine mandible. Am J Phys Anthropol 144:421-431.

Daegling DJ, Granatosky MC, McGraw WS, Rapoff AJ. 2011b. Spatial patterning of bone stiffness variation in the colobine alveolar process. Arch Oral Biol 56:220-230.

Daegling DJ, Grine FE. 1991. Compact bone distribution and biomechanics of early hominid mandibles. Am J Phys Anthropol 86:321-339. 
Daegling DJ, Hotzman JL, McGraw WS, Rapoff AJ. 2008. Material property variation of mandibular symphyseal bone in colobine monkeys. J Morphol 270:194-204.

Daegling DJ, Hotzman JL, McGraw WS, Rapoff AJ. 2009. Material property variation of mandibular symphyseal bone in colobine monkeys. J Morphol 270:194-204.

Daegling DJ, McGraw WS. 2001. Feeding, diet, and jaw form in West African Colobus and Procolobus. Int J Primatol 22:1033-1055.

Daegling DJ, McGraw WS. 2007. Functional morphology of the mangabey mandibular corpus: relationship to dental specializations and feeding behavior. Am J Phys Anthropol 134:50-62.

Daegling DJ, McGraw WS. 2009. Masticatory stress and the mechanics of "wishboning" in colobine jaws. Am J Phys Anthropol 138:306-317.

Dechow PC, Hylander WL. 2000. Elastic properties and masticatory bone stress in the macaque mandible. Am J Phys Anthropol 112:553-574.

Dechow PC, Nail GA, Schwartz-Dabney CL, Ashman RB. 1993. Elastic properties of human supraorbital and mandibular bone. Am J Phys Anthropol 90:291-306.

Dechow PC, Wang Q, Peterson J. 2010. Edentulation alters material properties of cortical bone in the human craniofacial skeleton: functional implications for craniofacial structure in primate evolution. Anat Rec A 293:618-629.

Delson E, Rosenberger AL. 1984. Are there any anthropoid primate living fossils? In: Eldredge N, Stanley SM, editors. Living fossils. New York: Springer Verlag. p 50-61.

Di Fiore A. 2004. Diet and feeding ecology of woolly monkeys in a western Amazonian rain forest. Int J Primatol 25:767-801.

Dumont ER, Davis JL, Grosse IR, Burrows AM. 2011. Finite element analysis of performance in the skulls of marmosets and tamarins. J Anat 218:151-162.

Eaglen RH. 1984. Incisor size and diet revisited: the view from a platyrrhine perspective. Am J Phys Anthropol 64:263-275.

Eng CM, Ward SR, Vinyard CJ, Taylor AB. 2009. The mechanics of the masticatory apparatus facilitate muscle force production at wide jaw gapes in tree-gouging common marmosets (Callithrix jacchus). J Exp Biol 212:4040-4055.

Evans AR. 2005. Connecting morphology, function and tooth wear in microchiropterans. Biol J Linn Soc 85:81-96.

Evans AR, Hunter J, Fortelius M, Sanson GD. 2005. The scaling of tooth sharpness in mammals. Ann Zool Fennici 42:603-613.

Fleagle JC. 1998. Primate adaptation and evolution. New York: Academic

Foster KD, Woda A, Peyron MA. 2006. Effect of texture of plastic and elastic model foods on the parameters of mastication. J Neurophysiol 95:3469-3479.

Gans C, Bock WJ. 1965. IV. The functional significance of muscle architecture-a theoretical analysis. Ergeb Anat Entwick 38:115-142.

Gantt DG. 1980. Implications of enamel prism patterns for the origin of the New World monkeys. In: Ciochon RL, Chiarelli AB editors. Evolutionary biology of the New World monkeys and continental drift. New York: Plenum. p 201-217.

Gibson LJ, Ashby MF. 1997. Cellular solids. Cambridge: Cambridge University Press.

Grant PR, Grant BR. 2002. Unpredictable evolution in a 30-year study of Darwin's finches. Science 296:707-711.

Greenfield LO. 1992. Relative canine size, behavior and diet in male ceboids. J Hum Evol 23:469-480.

Grine FE, Judex S, Daegling DJ, Ozcivici E, Ungar PS, Teaford MF, Sponheimer M, Scott J, Scott RS, Walker A. 2010. Craniofacia biomechanics and functional and dietary inferences in hominin paleontology. J Hum Evol 58:293-308.

Heiduck S. 1997. Food choice in masked titi monkeys (Callicebus personatus melanochir): selectivity or opportunism? Int J Primatol 18:487-502.

Hershkovitz P. 1977. Living New World monkeys (Platyrrhini). Chicago: University of Chicago Press.

Hiiemae KM, Kay RF. 1973. Evolutionary trends in the dynamics of primate mastication. In: Zingeser MR, editor. Symposia of the Fourth International Congress of Primatology, Vol. 3: Craniofacial biology of primates. Basel: S. Karger. p 28-64.
Hogg RT. 2010. Dental microstructure and growth in the Cebid Primates, PhD Thesis. City University of New York, New York (NY).

Hogg RT, Ravosa MJ, Ryan TM, Vinyard CJ. 2011. The functional morphology of the anterior masticatory apparatus in tree-gouging marmosets (Cebidae, Primates). J Morphol 272:833-849.

Hylander WL. 1979a. An experimental analysis of temporomandibular joint reaction force in macaques. Am J Phys Anthropol 51:433-456.

Hylander WL. 1979b. The functional significance of primate mandibular form. J Morphol 160:223-240.

Hylander WL. 1979c. Mandibular function in Galago crassicaudatus and Macaca fascicularis: an in vivo approach to stress analysis of the mandible. J Morphol 159:253-296.

Hylander WL. 1984. Stress and strain in the mandibular symphysis of primates: a test of competing hypotheses. Am J Phys Anthropol 61:1-46.

Hylander WL. 1985. Mandibular function and biomechanical stress and scaling. Am Zool 25:315-330.

Hylander WL. 1988. Implications of in vivo experiments for interpreting the functional significance of "robust" australopithecine jaws. In: Grine FE, editor. Evolutionary history of the "Robust" australopithecines. New York: Aldine de Gruyter. p 55-83.

Hylander WL, Bays R. 1979. An in vivo strain-gauge analysis of the squamosal-dentary joint reaction force during mastication and incisal biting in Macaca mulatta and Macaca fascicularis. Archs Oral Biol 24:689-697.

Hylander WL, Johnson KR. 1992. Strain gradients in the craniofacial region of primates. In: Davidovitch $\mathrm{Z}$, editor. The biological mechanisms of tooth movement and craniofacial adaptation. Columbus, OH: Ohio State University. p 559-569.

Hylander WL, Johnson KR. 1994. Jaw muscle function and wishboning of the mandible during mastication in macaques and baboons. Am J Phys Anthropol 94:523-547.

Hylander WL, Johnson KR. 1997. In vivo bone strain patterns in the zygomatic arch of macaques and the significance of these patterns for functional interpretations of craniofacial form. Am J Phys Anthropol 102:203-232.

Hylander WL, Johnson KR, Crompton AW. 1987. Loading patterns and jaw movements during mastication in Macaca fascicularis: a bone-strain, electromyographic, and cineradiographic analysis. Am J Phys Anthropol 72:287-314

Hylander WL, Picq PG, Johnson KR. 1991. Masticatory-stress hypotheses and the supraorbital region of primates. Am J Phys Anthropol 86:1-36.

Hylander WL, Ravosa MJ, Ross CF, Johnson KR. 1998. Mandibular corpus strain in primates: further evidence for a functional link between symphyseal fusion and jaw-adductor muscle force. Am J Phys Anthropol 107:257-271.

Hylander WL, Ravosa MJ, Ross CF, Wall CE, Johnson KR. 2000. Symphyseal fusion and jaw-adductor muscle force: an EMG study. Am J Phys Anthropol 112:469-492.

Izawa K. 1979. Foods and feeding behavior of wild black-capped capuchins (Cebus apella). Primates 20:57-76.

Kay RF. 1975. The functional adaptations of primate molar teeth. Am J Phys Anthropol 43:195-215.

Kay RF. 1981. The nut-crackers-a new theory of the adaptations of the Ramapithecinae. Am J Phys Anthropol 55:141-151.

Kendall K. 2001. Molecular adhesion and its applications: the Sticky Universe. New York: Springer.

Kinzey WG. 1974. Ceboid models for the evolution of hominoid dentition. J Hum Evol 3:193-203.

Kinzey WG. 1992. Dietary and dental adaptations in the Pitheciinae. Am J Phys Anthropol 88:499-514.

Larson SG, Stern JT. 2007. Humeral retractor EMG during quadrupedal walking in primates. J Exp Biol 210:1204-1215.

Lawn BR, Lee JJW, Constantino PJ, Lucas PW. 2009. Predicting failure in mammalian enamel. J Mech Behav Biomed Mater 2:3342.

Lucas PW. 2004. Dental functional morphology: how teeth work. Cambridge: Cambridge University Press.

Lucas P, Constantino P, Wood B, Lawn B. 2008a. Dental enamel as a dietary indicator in mammals. BioEssays 30:374-385. 
Lucas PW, Constantino PJ, Wood BA. 2008b. Inferences regarding the diet of extinct hominins: structural and functional trends in dental and mandibular morphology within the hominin clade. J Anat 212:486-500.

Maas MC, Dumont ER. 1999. Built to last: the structure, function, and evolution of primate dental enamel. Evol Anthropol 8:133152.

Marshall AJ, Wrangham RW. 2007. Evolutionary consequences of fallback foods. Int J Primatol 28:1219-1235.

Martin LB, Olejniczak AJ, Maas MC. 2003. Enamel thickness and microstructure in pitheciin primates, with comments on dietary adaptations of the middle Miocene hominoid Kenyapithecus. J Hum Evol 45:351-367.

Martin RD. 1990. Primate origins and evolution: a phyletic reconstruction. Princeton: Princeton University Press.

Masterson TJ. 1997. Sexual dimorphism and interspecific cranial form in two capuchin species: Cebus albifrons and C. apella. Am J Phys Anthropol 104:487-511.

Meehan RR, Burns SJ. 2007. Modeling cutting: plastic deformation of polymer samples indented with a wedge. J Manufact Sci Eng 129:477-484.

Menegaz RA, Sublett SV, Figueroa SD, Hoffman TJ, Ravosa MJ. 2009. Phenotypic plasticity and function of the hard palate in growing rabbits. Anat Rec A 292:277-284.

Møller E. 1966. The chewing apparatus: an electromyographic study of the action of the muscles of mastication and its correlation to facial morphology. Acta Physiol Scand 69 (Suppl 280):1-229.

Nogami Y, Natori M. 1986. Fine structure of the dental enamel in the Family Callitrichidae (Ceboidea, Primates). Primates 27:245258.

Nogami Y, Yoneda M. 1983. Structural patterns of enamel in the Superfamily Ceboidea. Primates 24:567-575.

Norconk MA. 1996. Seasonal variation in the diets of white-faced and bearded sakis (Pithecia pithecia and Chiropotes satanas) in Guri Lake, Venezuela. In: Norconk MA, Rosenberger AL, Garber PA, editors. Adaptive radiations of neotropical primates. New York: Plenum. p 403-423.

Norconk MA, Wright B, Conklin-Brittain NL, Vinyard CJ. 2009. Mechanical and nutritional properties of food as factors in platyrrhine dietary adaptations. In: Garber PA, Estrada A, Bicca-Marques JC, Heymann E, Strier K, editors. South American primates: testing new theories in the study of primate behavior, ecology, and conservation. New York: Springer. p 279-319.

Ottenhoff FAM, van der Bilt A, van der Glas HW, Bosman F, Abbink JH. 1996. The relationship between jaw elevator muscle surface electromyogram and simulated food resistance during dynamic condition in humans. J Oral Rehabil 23:270-279.

Palacios E, Rodriguez A, Defler TR. 1997. Diet of a group of Callicebus torquatus lugens (Humboldt 1812) during the annual resource bottleneck in Amazonian Colombia. Int J Primatol 18:503-522.

Peetz A. 2001. Ecology and social organization of the bearded saki Chiropotes satanas chiropotes (Primates: Pitheciinae) in Venezuela. Ecol Monogr 1:1-170.

Peterson J, Dechow PC. 2003. Material properties of the human cranial vault and zygoma. Anat Rec A 274:785-797.

Pirie PL. 1978. Allometric scaling in the postcanine dentition with reference to primate diets. Primates 19:583-591.

Popowics TE, Fortelius M. 1997. On the cutting edge: tooth blade sharpness in herbivorous and faunivorous mammals. Ann Zool Fennici 34:73-88.

Porter LM. 2001. Dietary differences among sympatric Callitrichinae in northern Bolivia: Callimico goeldii, Saguinus fuscicollis and S. labiatus. Int J Primatol 22:961-992.

Rapoff AJ, Rinaldi RG, Hotzman JL, Daegling DJ. 2008. Elastic modulus variation in mandibular bone: a microindentation study of Macaca fascicularis. Am J Phys Anthropol 135:100-109.

Ravosa MJ. 1991a. Structural allometry of the prosimian mandibular corpus and symphysis. J Hum Evol 20:3-20.

Ravosa MJ. 1991b. Interspecific perspective on mechanical and nonmechanical models of primate circumorbital morphology. Am J Phys Anthropol 86:369-396.
Ravosa MJ. 1996. Jaw morphology and function in living and fossil Old World monkeys. Int J Primatol 17:909-932.

Ravosa MJ, Hogg RT, Vinyard CJ. 2010. Exudativory and primate skull form. In: Burrows A, Nash LT, editors. Evolution of exudativory in primates. New York: Springer. p 169-185.

Ravosa MJ, Johnson KR, Hylander WL. 2000b. Strain in the galago facial skull. J Morphol 245:51-66.

Ravosa MJ, Kunwar R, Stock SR, Stack MS. 2007. Pushing the limit: Masticatory stress and adaptive plasticity in mammalian craniomandibular joints. J Exp Biol 210:628-641.

Ravosa MJ, Vinyard CJ, Gagnon M, Islam SA. 2000a. Evolution of anthropoid jaw loading and kinematic patterns. Am J Phys Anthropol 112:493-516.

Reed DA, Ross CF. 2010. The influence of food material properties on jaw kinematics in the primate, Cebus. Arch Oral Biol 55:946-962.

Rensberger JM. 1973. An occlusion model for mastication and dental wear in herbivorous mammals. J Paleo 47:515-528.

Richard AF. 1985. Primates in nature. New York: W.H. Freeman and Company.

Robinson BW, Wilson DS. 1998. Optimal foraging, specialization, and a solution to Liem's paradox. Am Nat 151:223-235.

Rosenberger AL. 1978. Loss of incisor enamel in marmosets. J Mammal 59:207-208.

Rosenberger AL. 1986. Platyrrhines, catarrhines and the anthropoid transition. In: Wood BA, Martin L, Andrews P, editors. Major topics in primate and human evolution. Cambridge: Cambridge University Press. p 66-88.

Rosenberger AL. 1992. Evolution of feeding niches in New World monkeys. Am J Phys Anthropol 88:525-562.

Rosenberger AL, Kinzey WG. 1976. Functional patterns of molar occlusion in platyrrhine primates. Am J Phys Anthropol 45: 281-298.

Ross CF. 2001. In vivo function of the craniofacial haft: the interorbital "pillar". Am J Phys Anthropol 116:108-139.

Ross CF. 2008. Does the primate face torque? In: Vinyard CJ, Ravosa MJ, Wall CE, editors. Primate craniofacial function and biology. Springer: New York. p 63-81.

Ross CF, Hylander WL. 1996. In vivo and in vitro bone strain in the owl monkey circumorbital region and the function of the postorbital septum. Am J Phys Anthropol 101:183-215.

Ross CF, Metzger KA. 2004. Bone strain gradients and optimization in vertebrate skulls. Ann Anat 186:387-396.

Ross CF, Porro L, Reed D. 2010. Bone strain and finite element modeling of the Cebus mandible during hard object feeding. Am J Phys Anthropol Suppl 141 (Suppl 50):252.

Ross CF, Ravosa MJ. 1993. Basicranial flexion, relative brain size, and facial kyphosis in nonhuman primates. Am J Phys Anthropol 91:305-324.

Rossie JB. 2006. Ontogeny and homology of the paranasal sinuses in Platyrrhini (Mammalia: Primates). J Morphol 267:1-40.

Ryan TM, Colbert M, Ketcham RA, Vinyard CJ. 2010. Trabecular bone structure in the mandibular condyles of gouging and nongouging platyrrhine primates. Am J Phys Anthropol 141:583-593.

Spencer MA. 2003. Tooth-root form and function in platyrrhine seed-eaters. Am J Phys Anthropol 122:325-335.

Strait S. 1993. Molar morphology and food texture among smallbodied insectivorous mammals. J Mammal 74:391-402.

Strait DS, Weber GW, Neubauer S, Chalk J, Richmond BG, Lucas PW, Spencer MA, Schrein C, Dechow PC, Ross CF, Grosse IR, Wright BW, Constantino P, Wood BA, Lawn B, Hylander WL, Wang Q, Byron C, Slice DE, Smith AL. 2009. The feeding biomechanics and dietary ecology of Australopithecus africanus. Proc Natl Acad Sci USA 106:2124-2129.

Strier KB. 1991. Diet in one group of woolly spider monkeys, or muriquis (Brachyteles arachnoides). Am J Primatol 23:113-126.

Taylor AB. 2002. Masticatory form and function in African apes. Am J Phys Anthropol 117:133-156.

Taylor AB, Eng CM, Anapol FC, Vinyard CJ. 2009. The functional correlates of jaw-muscle fiber architecture in tree-gouging and nongouging callitrichid monkeys. Am J Phys Anthropol 139: $353-367$. 
Taylor AB, Vinyard CJ. 2004. Comparative analysis of masseter fiber architecture in tree-gouging (Callithrix jacchus) and nongouging (Saguinus oedipus) callitrichids. J Morphol 261:276-285.

Taylor AB, Vinyard CJ. 2008. The relationship between jaw-muscle architecture and feeding behavior in primates: tree-gouging and nongouging gummivorous callitrichids as a naturalistic study. In: Vinyard CJ, Ravosa MJ, Wall CE, editors. Primate craniofacial function and biology. New York: Springer. p 241-262.

Taylor AB, Vinyard CJ. 2009. Jaw-muscle fiber architecture in tufted capuchins favors generating relatively large muscle forces without compromising jaw gape. J Hum Evol 57:710-720.

Teaford MF. 1985. Molar microwear and diet in the genus Cebus. Am J Phys Anthropol 66:363-370.

Teaford MF, Lucas PW, Ungar PS, Glander KE. 2006. Mechanical defenses in leaves eaten by Costa Rican howling monkeys (Alouatta palliata). Am J Phys Anthropol 129:99-104.

Terborgh J. 1983. Five new world primates: a study in comparative ecology. Princeton: Princeton University Press.

Thompson CL, Jackson EM, Stimpson CD, Horne WI, Vinyard CJ. 2011. The influence of experimental manipulations on chewing speed in vivo laboratory research in tufted capuchins (Cebus apella). Am J Phys Anthropol 145:402-414.

Ungar PS, Grine FE, Teaford MF. 2008. Dental mircowear and diet of the Plio-Pleistocene hominin Paranthropus boisei. PLoS One 3:e2044.

Vincent JFV, Jeronimidis G, Khan AA, Luyten H. 1991. The wedge fracture test. A new method for measurement of food texture. J Text Stud 22:45-57.

Vinyard CJ. 2008. Putting shape to work: making functional interpretations of masticatory apparatus shapes in primates. In: Vinyard CJ, Ravosa MJ, Wall CE, editors. Primate craniofacial function and biology. New York: Springer. p 357-385.

Vinyard CJ, Ravosa MJ. 1998. Ontogeny, function, and scaling of the mandibular symphysis in papionin primates. J Morphol 235: $157-175$.

Vinyard CJ, Ravosa MJ, Wall CE, Williams SH, Johnson KR, Hylander WL. 2007. Jaw-muscle function and the origin of primates. In: Ravosa MJ, Dagosto M, editors. Primate origins and adaptations. New York: Kluwer Press. p 179-231.

Vinyard CJ, Ryan TM. 2006. Cross-sectional bone distribution in the mandibles of gouging and non-gouging platyrrhines. Int J Primatol 27:1461-1490.

Vinyard CJ, Taylor AB. 2010. A preliminary analysis of the relationship between jaw-muscle architecture and jaw-muscle electromyography during chewing across primates. Anat Rec 293: 572-582.

Vinyard CJ, Wall CE, Williams SH, Hylander WL. 2003. Comparative functional analysis of skull morphology of tree-gouging primates. Am J Phys Anthropol 120:153-170.
Vinyard CJ, Wall CE, Williams SH, Mork AL, Armfield BA, Melo LCO, Valença-Montenegro MM, Valle YBM, Borstelmann de Oliveira MA, Lucas PW, Schmitt D, Taylor AB, Hylander WL. 2009. The evolutionary morphology of tree gouging in marmosets. In: Ford SM, Davis LC, Porter LM, editors. The smallest anthropoids: the Marmoset/Callimico radiation. New York: Springer. p 395-410.

Wallace RB. 2005. Seasonal variations in diet and foraging behavior of Ateles chamek in a southern Amazonian tropical forest. Int $\mathrm{J}$ Primatol 26:1053-1075.

Wang Q, Ashley DW, Dechow PC. 2010. Regional, ontogenetic, and sex-related variations in elastic properties of cortical bone in baboon mandibles. Am J Phys Anthropol 141:526-549.

Wang Q, Dechow PC. 2006. Elastic properties of external cortical bone in the craniofacial skeleton of the rhesus monkey. Am J Phys Anthropol 131:402-415.

Warfel M. 1997. MomentMacroJ v1.3. Baltimore: Ruff CB.

Williams JG. 1998. Friction and plasticity effects in wedge splitting and cutting fracture tests. J Mater Sci 33:5351-5357.

Williams SH, Vinyard CJ, Glander KE, Deffenbaugh M, Teaford M, Thompson CL. 2008b. A preliminary report on a telemetry system for assessing jaw-muscle function in free-ranging primates. Int $\mathrm{J}$ Primatol 29:1441-1453.

Williams SH, Vinyard CJ, Wall CE, Hylander WL. 2009. An in vivo analysis of mandibular corpus bone strain in goats and alpacas: implications for understanding the biomechanics of mandibular form in selenodont artiodactyls. J Anat 214:65-78.

Williams SH, Wall CE, Vinyard CJ, Hylander WL. 2008a. Symphyseal fusion in selenodont artiodactyls: new insight from in vivo and comparative data. In: Vinyard CJ, Ravosa MJ, Wall CE, editors. Primate craniofacial function and biology. New York: Springer. p 39-61.

Williams SH, Wright BW, Truong VD, Daubert CR, Vinyard CJ. 2005. Mechanical properties of foods used in experimental studies of primate masticatory function. Am J Primatol 67:329-346.

Woda A, Foster K, Mishellany A, Peyron MA. 2006. Adaptation of healthy mastication to factors pertaining to the individual or to the food. Physiol Behav 89:28-35.

Wright BW. 2004. Ecological distinctions in diet, food toughness, and masticatory anatomy in a community of six Neotropical primates in Guyana, South America, PhD Thesis. Urbana-Champaign: University of Illinois.

Wright BW. 2005. Craniodental biomechanics and dietary toughness in the genus Cebus. J Hum Evol 48:473-492.

Xu X, Schneider E, Chien AT, Wudl F. 1997. Nature's high-strength semitransparent film: the remarkable mechanical properties of Prunus serrula bark. Chem Mater 9:1906-1908.

Zingeser MR. 1973. Dentition of Brachyteles arachnoides with reference to Alouttine and Atelinine affinities. Folia Primatol 20: $351-390$. 